ISSN:1308-8173

Geliş Tarihi: 07.10.2020
E-ISSN: 1308-8505

Kabul Tarihi: 30.09 .2021
YIL:2021

Online Yayın: 11.11.2021

ÖZGÜN ARAŞTIRMA
Cilt:36 Sayı:4 Sayfa:893-911

Doi:10.24988/ije.807286

\title{
Stokastik Faiz Oranı Modelleri (CIR / Vasicek) ile Faiz Oranlarının Modellenmesi ve Getiri Eğrisi Tahmini
}

\section{Önder BÜBERKÖKÜ1}

\section{Özet}

Bu çalışmada stokastik diferansiyel denklemlerine dayanan Vasicek ve CIR modelleri gösterge faiz oranına uygulanarak, modellerin faiz oranı öngörü performansları incelenmiş, getiri eğrisi ve forward verim eğrisi tahmin edilmiștir. Analizler tüm dönemin yanı sıra ICSS algoritmasına bağlı olarak belirlenen farklı volatilite dönemleri dikkate alınarak da yapılmiştır. Modellerin performanslarının analizinde RMSE, ME, MSE, MAE, MAPE ve Theil's U kriterlerinden yararlanılmıștır. Bulgular, belirgin bir șekilde CIR modelinin performansının Vasicek modelinin performansından daha iyi olduğu sonucuna işaret etmektedir. Çalışma bulgularının para politikası uygulamaları, sabit getirili finansal varlıkların fiyatlanması ve getiri eğrilerinin tahmini gibi konular açısından oldukça önemli bilgiler sunduğu düşünülmektedir.

Anahtar kelimeler: Getiri eğrisi tahmini, CIR modeli, Vasicek modeli, Stokastik diferensiyel denklemler

Jel Kodu: C53, E43, E47

\section{Modelling Interest Rates, and Forecasting the Yield Curve with Stochastic Interest Rate Models (CIR and Vasicek) \\ Abstract}

In this study, the CIR and Vasicek models, both of which are based on stochastic differential equations, are applied to benchmark government bond interest rates. After this, the interest rate forecasting performances of these models are examined for whole periods as well as for sub-periods determined based on the ICSS algorithm. RMSE, MSE, MAE, ME, and MAPE loss functions along with Theil's $U$ method are used to analyse the forecasting performances of the models. The results show that the CIR model performs better than the Vasicek model. The findings of the study have important implications for monetary policy applications, fixed income security valuations, and yield curve estimations.

Keywords: Yield curve estimation, CIR model, Vasicek model, Stochastic differential equations Jel Codes: C53, E43, E47

\section{GİRIS}

Faiz oranlarının seviyesinin makroekonomik ve finansal denge açısından oldukça önemli işlevleri olduğu bilinmektedir. Çünkü, faiz oranlarındaki değişimler enflasyon oranı, döviz kuru volatilitesi ve sermaye akımları gibi değişkenler üzerinde etkili olabilmektedir. Bunun yanı sıra çeşitli vadelerdeki spot faiz oranlarının bir araya getirilmesi ile oluşturulan getiri eğrileri de para politikası kararlarının etkinliği, sabit getirili spot finansal varlıkların ve bu finansal varlıklar üzerine yazılı türev ürünlerin fiyatlanması, forward verim eğrilerinin elde edilmesi ve özel sektör tahvil / bonolarının risk primlerinin belirlenebilmesi gibi konularda oldukça önemli işlevlere sahiptir (Chua, Suardi ve Tsiaplias, 2013: 442; Almeida ve Vicente, 2008:2695).Örneğin, literatürde normal koşullarda merkez bankalarının daha çok kısa vadeli faiz oranları üzerinde önemli derecede etkili oldukları ifade edilmektedir. Fakat, toplam talep, toplam arz ve üretim düzeyi gibi reel faktörlerin daha çok uzun vadeli reel faiz oranlarından etkilendiği bilinmektedir. Bu nedenle merkez bankalarının

ATIF ÖNERİsi (APA): Büberkökü, Ö. (2021). Stokastik Faiz Oranı Modelleri (CIR / Vasicek) ile Faiz Oranlarının Modellenmesi ve Getiri Eğrisi Tahmini. İzmir Íktisat Dergisi. 36(4). 893-911. Doi: 10.24988/ije.807286

1, Doç. Dr, Van Yüzüncü Yıl Üniversitesi, Erciş İşletme Fakültesi, Erciş/ Van, Türkiye

EMAIL: onderbuber@gmail.com. ORCID: 0000-0002-7140-557X 


\section{Ö. BÜBERKÖKÜ}

kısa vadeli faiz oranları konusunda aldıkları kararlar sonrasında uzun vadeli reel faiz oranlarının da politika hedefleri doğrultusunda değişmesi gerekmektedir. $\mathrm{Bu}$ durumun gerçekleşip gerçekleşmediğinin veya gerçekleşti ise hangi oranda gerçekleştiğinin belirlenebilmesinde ise getiri eğrilerinden yararlanılmaktadır (Herrala, 2009:5-6). Bunun yanı sıra, finansal varlıkların etkin bir şekilde fiyatlanması ve doğru yatırım kararlarının verilebilmesi için de ihtiyaç duyulan her vade için spot faiz oranlarının hesaplanması ve forward verim eğrilerinin oluşturulması gerekmektedir.

Getiri eğrileri spot faiz oranlarının bir araya getirilmesi ile oluşturulduğundan, spot faiz oranları kullanılarak sabit getirili finansal varlıkların nakit akışlarının tekabül ettiği dönemlere ilişkin iskonto faktörleri belirlenebilmekte ve forward verim eğrileri hesaplanabilmektedir. Forward verim eğrileri de hem vadeler arası yatırım stratejilerinin oluşturulması hem de arbitraj olanaklarının analizi konularında oldukça önemli bilgiler sunmaktadır.

Fakat bu kadar önemli özelliklerinin bulunmasına rağmen faiz oranlarının ve getiri eğrilerinin modellenmesinin modern finans teorisinin en karmaşık konularından biri olduğu ifade edilebilir (Benninga ve Wiener, 1998:1). Çünkü, ilgili analizlerin basit bir şekilde yapılabilmesi için piyasada işlem gören ve ihtiyaç duyulan her vadeye karşılık gelen hazine bonolarının ve / veya sabit faizli tahvillerin doğal olarak bulunması gerekmektedir. Fakat pratik hayattaki işleyişin buna imkan verdiğini söylemek oldukça güçtür. $\mathrm{Bu}$ nedenle gerek spot faiz oranlarının gerekse getiri eğrilerinin gelişmiş yöntemler kullanarak modellenmesi gerekmektedir. Literatürde de bu amaçla kullanılan çeşitli modeller bulunmaktadir.

$\mathrm{Bu}$ çalışmada bu alanın temel modelleri olmalarına ve uluslararası literatürde oldukça ilgi görmelerine bağlı olarak birer stokastik faiz oranı modeli olan Vasicek (1977) ve CIR (Cox, Ingersoll-Ross 1985) modelleri üzerinde durulmuştur. Bu modeller yardımıyla ihtiyaç duyulan her vade için spot faiz oranları ve bugünkü değer faktörleri hesaplanabilmekte ve getiri eğrileri ile forward verim eğrileri elde edilebilmektedir. Tüm bu analizler için de sadece kısa vadeli nominal faiz oranlarına ihtiyaç duyulmaktadır. Çünkü, geleneksel Vasicek ve CIR modelleri tek faktörlü modellerdir. Bir diğer ifadeyle bu modellerde tek stokastik faktör ortalamaya dönem eğilimi sergileyen kısa vadeli spot faiz oranlarıdır ve bu modeller, çeşitli vadelere sahip faiz oranları arasında mükemmel bir korelasyon olduğu varsayımına dayanmaktadır (Bao ve Yuan, 2013:267).

$\mathrm{Bu}$ çalışmanın amacı Türkiye ekonomisi için CIR ve Vasicek modellerinin gösterge faiz oranlarına uygulanması ve tüm dönemin yanı sıra alternatif volatilite dönemleri de dikkate alınarak bu modellerin performanslarının karşılaştırılmasıdır. Bu kapsamda bu çalışmada ilgili modellerin parametreleri tahmin edilmiş, çeşitli dönemler için faiz oranı tahminleri gerçekleştirilmiş, spot faiz oranları hesaplanmış ve getiri eğrisi ile forward verim eğrisi tahmin edilmiştir. Çalışmanın literatüre çeşitli açılardan katkı sağlayacağı düşünülmektedir. Öncelikle, ulusal yazına bakıldığında bu alanda henüz oldukça sınırlı sayıda çalıșmanın olduğu görülmektedir. $\mathrm{Bu}$ nedenle ulusal yazında bu alanda bir boşluk olduğu ifade edilebilir. İkinci olarak bu çalışmada CIR ve Vasicek modellerinin performansları sadece tek bir dönem için değil Türk faiz oranı piyasasında meydana gelen ve ICSS algoritması ile belirlenen alternatif volatilite dönemleri de dikkate alınarak, toplamda 4 farklı dönem için karşılaştırılmıştır. Son olarak da bu modellerin performansları karşılaştırılırken farklı yaklaşımlara karşı dirençli (robust) sonuçlar elde edebilmek amacıyla altı farklı kriterden yararlanılmıştır.

Çalıșma beș bölümden oluşmaktadır. İkinci bölümde literatür taraması bulunmakta, üçüncü bölümde analizlerde kullanılan veri ve metodoloji yer almakta; dördüncü bölümde 
bulgular değerlendirilmekte, beșinci bölümde ise sonuçlar yer almaktadır.

\section{LITERATÜR TARAMASI}

Konunun önemine bağlı olarak faiz oranı modellerinin uluslararası literatürde oldukça ilgi gördükleri ifade edilebilir. Örneğin, Babbs ve Nowman (1998) İngiltere ekonomisi için iki faktörlü Vasicek modeli ile tek faktörlü Vasicek modelinin performanslarını karşılaştırdıkları çalışmalarında iki faktörlü Vasicek modelinin daha uygun bir model olduğu sonucuna ulaşmışlardır. Nath ve Nowman (2001) İngiltere ekonomisi için iki faktörlü CIR modelinin performansını tek faktörlü CIR modelinin performansı ile karşılaștırdıkları çalışmalarında iki faktörlü CIR modelinin daha iyi performans sergilediği sonucuna ulaşmışlardır. Zeytun ve Gupta (2007) Kanada ekonomisi için CIR ve Vasicek modellerini inceledikleri çalışmalarında bu iki modelin temel karakteristik özelliklerinin birbirine oldukça benzer olduğu sonucuna ulaşmışlardır.Li, Clemons, Young ve Zhu (2008) CIR ve Vasicek modellerinin performanslarını karşılaştırdıkları çalışmalarında CIR modelinin daha uygun bir model olduğu sonucuna ulaşmışlardır. Zhang, Su ve Yang (2009) Çin ekonomisi için CIR ve Vasicek modellerinin performanslarını karşılaştırdıkları çalışmalarında Vasicek modelinin kısmen daha iyi performans sergilediği sonucuna ulaşmışlardır. van Elen (2010) Kanada ekonomisi için Nelson-Siegel, CIR ve Vasicek modellerinin performanslarını karşılaştırdı çalışmasında en uygun modelin Nelson-Siegel modeli olduğu sonucuna ulaşmıștır. Ma, Liu ve Lan (2014) Çin ekonomisi için iki faktörlü Vasicek modelini inceledikleri çalışmalarında bu modelin Çin faiz oranı piyasası için uygun bir model olduğu sonucuna ulaşmışlardır. Moreno ve Platania (2015) ABD ekonomisi için geleneksel CIR modeli ile kendi geliştirdikleri döngüsel (Cyclical) CIR modelini karşılaştırdıkları çalışmalarında döngüsel CIR modelinin daha uygun bir model olduğu sonucuna ulaşmışlardır. Orlando, Mininni ve Bufalo (2019) Euro bölgesi için yeni bir metodolojik yaklașımla tahmin ettikleri CIR modelinin performansinı inceledikleri çalışmalarında, bu modelin faiz oranı piyasalarına uyumunun iyi olduğunu ve EWMA yönteminden daha iyi performans sergilediğini ifade etmişlerdir.

Ulusal yazına bakıldığında ise bu konuda oldukça sınırlı sayıda çalışma olduğu görülmektedir. $\mathrm{Bu}$ kapsamda ulaşılabilen çalışmalara bakıldığında Bayazıt (2004) Türkiye ekonomisi için cari dönem getiri eğrisini kullanarak gelecek dönem getiri eğrisini tahmin etmeye çalıştığı çalışmasında getiri eğrisindeki eksik gözlemleri NelsonSiegel modeli ile tahmin etmiş, gelecek dönemin getiri eğrisinin tahmininde ise Vasicek modelinden yararlanmıştır. Yolcu (2005) çalışmasında Türkiye ekonomisi için Vasicek ve genişletilmiş Vasicek modellerinin parametrelerini tahmin etmiş ve üçlü faiz haddi ağacını oluşturulmuștur. Zeytun (2005) faiz oranı piyasası için stokastik volatiliteli Vasicek modelinin performansını incelediği çalışmasında bu modelin volatiliteyi öngörme performansının geleneksel ARCH ve GARCH modellerininkinden daha iyi olduğu sonucuna ulaşmıștır. Önalan (2009) Vasicek ve CIR modellerini VIX endeksi ile 3 ay vadeli ABD hazine bonosu faiz oranlarına uyguladığı çalışmasında modellerin VIX endeksini modellemede başarılı olmadığı fakat faiz oranlarını modellemedeki performanslarının iyi olduğu sonucuna ulaşmıştır. Şahin ve Genç (2009) sekiz ayrı kısa vadeli faiz oranı modelinin performansını Türkiye ekonomisi için inceledikleri çalışmalarında CIR ve Brennan-Schwartz modellerinin daha uygun modeller oldukları sonucuna ulaşmışlardır. Dağıstan (2010) ise içerisinde CIR ve Vasicek modellerinin de bulunduğu altı farklı kısa vadeli faiz oranı modelini Amerika, Almanya ve Kanada ekonomilerinin faiz oranı piyasalarına uyguladığı çalışmasında tüm modeller için tahvil fiyatlama örnekleri sunmuş ve risk simülasyonlarına dayalı analizlere yer vermiştir. 


\section{Ö. BÜBERKÖKÜ}

\section{VERI VE METODOLOJI}

\subsection{Veri}

Çalışma 1 Ocak 2002 ile 4 Ağustos 2016 dönemini kapsamakta ve günlük verilerden oluşmaktadır. Veriler FINNET veri tabanından alınmıştır. Normalde CIR ve Vasicek modelleri birer kısa vadeli faiz oranı modelleridir. $\mathrm{Bu}$ nedenle salt teorik açıdan bakıldığında bu modellerin piyasadaki kısa vadeli nominal faiz oranlarına uygulanması beklenebilir. Fakat, uygulamaya bakıldığında bu modellerin 2 yıl vadeli faiz oranlarından 25 yll vadeli faiz oranlarına kadar çok farklı vadeye sahip faiz oranlarına uygulandığı görülmektedir (Örneğin bakınız: Babbs ve Nowman, 1998; Nath ve Nowman, 2001; Moreno ve Platania, 2015). Bu nedenle bu çalışmada CIR ve Vasicek modelleri gösterge faiz oranlarına uygulanmıştır. Gösterge faiz oranları vadesine iki yıl kalmış ve en yüksek işlem hacmine sahip devlet tahvilinin faiz oranlarını ifade etmektedir.Çalışmada gösterge faiz oranlarının kullanılmasının temel nedeni bu faiz oranlarının piyasada belirlenen diğer birçok faiz oranı için gösterge niteliği taşımasından kaynaklanmaktadır.

\subsection{Metodoloji}

\subsubsection{Vasicek ve CIR Modellerinin Temel Özellikleri}

$\mathrm{Bu}$ çalışmada faiz oranlarının modellenmesinde Vasicek ve CIR modellerinden yararlanılmıştır. Bunun bazı önemli nedenleri bulunmaktadır. Öncelikle Vasicek modeli kısa vadeli faiz oranlarının modellenmesine ve getiri eğrilerinin elde edilmesine dönük olarak geliştirilen ilk önemli stokastik faiz oranı modellerinden birini temsil etmektedir. CIR modeli ise stokastik faiz oranı modellemelerine dönük olarak Vasicek modelinden sonraki en önemli adımlardan birini temsil etmektedir (Schulmerich, 2015:82). İkinci olarak Vasicek ve CIR modelleri kısa vadeli faiz oranlarının

\footnotetext{
${ }^{1}$ Literatürde yaygın bir şekilde ifade edildiği gibi gibi herhangi bir değișkenin $(x)$ Wiener sürecini takip ettiğinin ifade edilebilmesi için oldukça kısa bir zaman aralığında $(\Delta t)$ bu değişkende meydana gelen değișimin, $\Delta x=\varepsilon \sqrt{(\Delta t)}$ şeklinde olması ve herhangi iki farklı kısa
}

ortalamaya dönem eğilimi sergiledikleri varsayımına dayanmaktadır ki bu varsayım bu iki modele dayalı olarak yapılan analizlere önemli bir gerçekçilik katmaktadır (Joshi ve Swertloff, 1999:107).Üçüncü olarak bu iki modelin parametrelerinin tahmin edilmesinin ve bu modellere dayalı diğer analizlere dönük hesaplamaların göreceli olarak kolay olması da bu modellerin diğer bir önemli avantajını oluşturmaktadır (Brigo ve Mercurio, 2001: 54).Son olarak da bu iki model hem uygulamada hem de literatürde en çok kullanılan modeller arasında yer almakta ve diğer birçok kısa vadeli faiz oranı modelinin de teorik altyapısının çıkış noktasını oluşturmaktadır (Albano, Rocca ve Perna, 2019: 6; Rogers ve Stummer, 2000: 46-50).

$\mathrm{Bu}$ açıklamalar ışığında tek faktörlü stokastik diferansiyel denklemlerine dayanan Vasicek ve CIR modellerinin genel yapısı sırasıyla Denklem (1) ve (2)'de gösterilmiștir. Alternatif denklem formasyonları içinse Sinkala, Leach ve O'Hara (2008), Mamon (2004); Bakkaloglu, Aziz ve Mahomed (2007); Khalique ve Motsepa'nın (2018) çalışmalarına bakılabilir.

$d r_{\mathrm{t}}=\theta\left(\mu-\mathrm{r}_{\mathrm{t}}\right) \mathrm{dt}+\sigma \mathrm{dW}_{\mathrm{t}}$

$\mathrm{dr}_{\mathrm{t}}=\theta\left(\mu-\mathrm{r}_{\mathrm{t}}\right) \mathrm{dt}+\sigma \sqrt{\mathrm{r}_{\mathrm{t}}} \mathrm{dW}$

Burada $r_{t}$, cari dönemdeki nominal spot faiz oranını; $d r_{t}$, faiz oranlarındaki değişimi; $\mu$, faiz oranlarının uzun dönemli denge değerini; $\theta$, faiz oranlarının uzun dönemli denge değerlerine dönme hızını; $\sigma$, standart sapma parametresini; $\Delta t$, zaman aralığını; $\left\{W_{t}, t \geq 0\right\}$ ise standart Wiener sürecini göstermektedir ${ }^{1}$.

Bu her iki modelde de spot faiz oranlarının $\left(r_{t}\right)$ sürekli bir Markovyen stokastik süreç izlediği varsayılmaktadır. Wiener süreci de Markovyen stokastik sürecin özel bir durumunu ifade etmektedir. Çünkü, Wiener süreci bir değişkenin değerinde zamanla meydana gelen olasılıksal gelişimi ifade eden stokastik bir

zaman aralığındaki $\Delta x$ değerlerinin birbirinden bağımsız olması gerekmektedir. Burada $\varepsilon$, sıfır ortalamalı ve bir standart sapmalı standart normal dağılımı ifade etmektedir. 
süreçtir ve Markovyen özelliğine de sahip olması nedeniyle bir değişkenin gelecekte alabileceği değerlerin tahminde bu değişkenin geçmiş dönemlerde aldığı değerlerin herhangi bir etkisinin bulunmadığını varsaymaktadır (Csajkova, 2007: 8). Bir diğer ifadeyle Markovyen yaklaşımda bir değişkenin gelecekte alabileceği değerlerin tahmini için ihtiyaç duyulan tüm bilgilerin bu değişkenin cari dönem değeri içerisinde bulunduğu varsayımı yer almaktadır (Georges, 2003: 5). $\mathrm{Bu}$ nedenle bu özelliklere sahip stokastik bir süreçte, ilgili değișkenin cari dönem değeri referans alındıktan sonra daha sonraki dönemlere ilişkin değerlerin üretilmesi de sadece bir önceki duruma bağlı olan koşullu olasılıklar ile ifade edilmektedir (Çelik, 2013:11).

\subsubsection{Vasicek ve CIR Modellerinin Ortalamaya Dönme Özelliği}

Ornstein-Uhlenbeck sürecine dayanan Vasicek modeli ile CIR modelinin nominal faiz oranlarının ortalamaya dönme eğilimi sergiledikleri varsayımı, literatürde de yaygın bir şekilde ifade edildiği gibi kısa vadeli faiz oranlarının uzun dönemli denge değerinin üzerinde olması durumunda belli bir süre sonra azalarak uzun dönemli denge değerine doğru hareket edeceklerini veya kısa vadeli faiz oranlarının uzun dönemli denge değerinin altında olması durumunda ise belli bir süre sonra bu sefer artarak uzun dönemli denge değerine yakınsayacakları anlamına gelmektedir. $\mathrm{Bu}$ durumun da genel olarak pratikte faiz oranı piyasalarında gözlemlenen durum ile uyumlu olduğu ifade edilebilir. Çünkü Schulmerich (2015:94) tarafindan da ifade edildiği gibi iktisadi ve finansal açıdan faiz oranlarının yüksek olması önce ekonomik aktivitenin daha sonra da enflasyon oranlarının azalmasına yol açabilmektedir. Bu durum da özellikle enflasyon hedeflemesine dayalı bir para politikası uygulayan merkez bankalarının faiz oranlarını düşürmesine sebep olabilmektedir. Faiz oranlarının düşük olması ise önce ekonomik aktivitenin daha sonra da enflasyon oranlarının artmasina yol açabilmekte; bu durum da merkez bankalarının faiz oranlarını artırmasina sebep olabilmektedir. İşte Ornstein-Uhlenbeck yaklaşımı da bu ortalamaya dönme sürecinin stokastik bir süreç olduğunu ifade etmekte ve bu süreci bir durağan Gauss-Markov süreci olarak modellemektedir (Doob, 1942; Bibbona, Panfilo, Tavella, 2008).

\subsubsection{Vasicek ve CIR Modelleri Arasındaki Bazı Yapısal Farklılıklar}

Vasicek ve CIR modellerinin daha önceki aşamalarda belirtilen benzer özelliklerine rağmen bu modeller arasında bazı önemli farklılıklar da bulunmaktadır. Örneğin Ahmed, Nkurunziza ve Liu (2009:256), Orlando, Mininni ve Bufalo (2019a:268) ile Orlando, Mininni ve Bufalo (2019b:371-372) tarafından da ifade edildiği gibi Denklem (1) ve (2) incelendiğinde Vasicek ve CIR modellerinin aslında iki temel bileşenden oluştuğu anlaşılmaktadır. Bunlar eğilim bileşeni (drift component ) ile tesadüfi süreci içeren difüzyon bileşenidir (diffusion component). Hem Vasicek hem de CIR modeli için eğilim bileșeni " $\theta\left(\mu-r_{t}\right)$ " ile temsil edilmektedir. Bu bileşen nominal faiz oranlarının ortalamaya dönme eğilimini temsil etmektedir. Bu iki model arasındaki temel fark ise difüzyon bileşeninden kaynaklanmaktadır. Vasicek modelinde difüzyon bileşeni sabit bir volatilite parametresi ile ölçeklendirilip (scaled) " $\sigma W_{t}$ " ile temsil edilirken; CIR modelinde difüzyon bileşeni " $\sigma \sqrt{r_{t}}$ " ile ölçeklendirilip; " $\sigma \sqrt{r_{t}} d W_{t}$ " ile temsil edilmektedir. Bu tür bir yaklaşım sayesinde de Vasicek modelinin aksine CIR modeli negatif nominal faiz oranlarının üretilmesini engelleyebilmektedir. Çünkü bu yaklaşım sayesinde Vasicek modelinin temel varsayımlarından biri olan nominal faiz oranlarının şartlı volatilitesinin sabit olduğu varsayımının yerini nominal faiz oranlarının volatilitesinin değișen varyans özelliği sergilediği varsayımı almaktadır. CIR modelindeki bu yaklaşım sayesinde de nominal faiz oranlarındaki artışlar volatilitenin artmasına, nominal faiz oranlarındaki düşüşler ise volatilitenin düşmesine yol açmaktadır. 


\section{Ö. BÜBERKÖK̈̈}

Dolayısıyla nominal faiz oranları sıfıra yaklaştığında volatilite de oldukça düşüş seviyelere gerilediğinden CIR modelinin negatif nominal faiz oranları üretmesi de engellemektedir (Joshi ve Swertloff, 1999:107).

\subsubsection{Vasicek ve CIR Modellerinin Kullanımı}

$\mathrm{Bu}$ açıklamalar ışığında Vasicek ve CIR modelleri ekonometrik analizlerde kullanılırken kısa vadeli faiz oranlarında meydana gelen değişimler sırasıyla Denklem (3) ve (4)'teki gibi ifade edilmektedirler²:

$\Delta r_{t}=\theta\left(\mu-r_{t}\right) \Delta t+\sigma \sqrt{\Delta t} Z$

$\Delta r_{t}=\theta\left(\mu-r_{t}\right) \Delta t+\sigma \sqrt{\Delta t} \sqrt{r_{t}} Z$

Burada $\Delta t$, zaman aralığını; $Z$ ise $Z \sim N(0,1)$ olacak şekilde standart normal dağılımı ifade etmektedir ${ }^{3}$.Burada ayrıca $\theta>0 ; \mu>0$ ve $\sigma>$ 0 koşullarının sağlanması beklenmektedir.

Vasicek ve CIR modelleri kapsamında bir dönem sonraki spot faiz oranları $\left(r_{t 1}\right)$ ise sirasıyla Denklem (5) ve (6)'daki gibi hesaplanmaktadır:

$$
\begin{gathered}
r_{t 1}=r_{t}+\Delta r_{t}=r_{t}+\theta\left(\mu-r_{t}\right) \Delta t+\sigma \sqrt{\Delta t} Z \\
r_{t 1}=r_{t}+\Delta r_{t}=r_{t}+\theta\left(\mu-r_{t}\right) \Delta t+\sigma \sqrt{\Delta t} \sqrt{r_{t}} Z
\end{gathered}
$$

$\mathrm{Bu}$ duruma somut bir örnek vermek gerekirse, örneğin CIR modeli için model parametreleri tahmin edilmiş ve Tablo 1'deki değerlerle uyumlu olacak şekilde $\theta=0.5335 ; \mu=0.1111$; $\sigma=0.1453$ çıkmış olsun. Ayrıca günlük veri kullanıldığından bir yılda 252 işgünü olduğu varsayımı altında $\Delta t=1 / 252=0.004$ olarak hesaplansın. Çalıșmanın başlangıç tarihi olan 1 Ocak 2002 tarihi itibariyle cari dönem faizi $\left(r_{t}\right)$ $\% 70.02$ olsun. Klasik Wiener süreci kapsamında $\quad \varepsilon=-1.21956$ olacak şekilde

\footnotetext{
${ }^{2}$ CIR ve Vasicek modelleri tahmin edilirken iki aşamalı bir süreç izlenmektedir. İlk aşamada en küçük kareler yöntemi kullanılarak CIR ve Vasicek modellerinin parametrelerinin tahmininde kullanılacak başlangıç değerleri (initial values) elde dilmektedir. Fakat, en küçük kareler yöntemi belli durumlarda tutarsız (inconsistent) ve yanlı (biased) sonuçlar üretebilmektedir. Bu nedenle de ikinci aşamada en çok olabilirlik yöntemi (Maximum likelihood estimation,
}

belirlenmiș ise CIR modeli tarafından bir gün sonrası için tahmin edilen gösterge faiz oranı aşağıdaki gibi hesaplanmaktadır:

$\Delta r_{t}=0.5335 *(0.1111-0.7002) * 0.004+$ $0.1453 * \sqrt{0.004} * \sqrt{0.7002} *-1.21956$

$\Delta r_{t}=-0.010635156$,

$r_{t 1}=r_{t}+\Delta r_{t}$

$r_{t 1}=0.7002-0.010635156$

$r_{t 1}=\% 68.96$

$\mathrm{Bu}$ hesaplamalar incelenen dönemin tamamını kapsayacak şekilde her bir gün sonrasına ait yeni $r_{t}$ ve $\varepsilon_{t}$ için günlük bazda ardışık olarak yapıldığında incelenen dönemin tamamını kapsayan tahmini gösterge faiz oranları elde edilmektedir.

Fakat, daha önce de ifade edildiği gibi CIR modelinin aksine Vasicek modeli negatif nominal faiz oranları üretebilmektedir. $\mathrm{Bu}$ durumun gerçekleşme olasılığı da literatürde Denklem (7)'deki gibi hesaplanmaktadır (van Elen, 2010: 9):

$$
P\left(r_{t} \leq 0\right)=\Phi\left(\frac{-r_{t}-\theta\left(\mu-r_{t}\right) \Delta t}{\sigma \sqrt{\Delta t}}\right)
$$

Bunun yanı sıra Vasicek modelinin negatif nominal faiz oranları üretme olasılığının daha çok kısa vadede geçerli bir durum olduğu da belirtilmelidir. Çünkü, Vasicek modeli sabit katsayılı Ornstein-Uhlenbeck sürecine dayanmaktadır. Ornstein-Uhlenbeck sürecinin şartlı ortalama ve varyans değerleri ise uzun dönemde $(T \rightarrow \infty)$ Denklem (8) ve (9)'daki gibi tanımlanmaktadır:

$$
\begin{aligned}
& E_{t}\left(r_{T}\right)=\mu \\
& \operatorname{Var}_{t}\left(r_{T}\right)=\frac{\sigma^{2}}{2 \theta}
\end{aligned}
$$

MLE) kullanılarak ilgili modellerin parametrelerinin optimal değerleri elde edilmektedir.

${ }^{3} \mathrm{Bu}$ dağılım parametresi Vasicek ve CIR modelleri için ortak bir dağılım parametresi olup; ilgili dağılım varsayımı altında her defasında farklı değerler üretebilmektedir. Analizlerde doğrudan CIR ve Vasicek modellerinin performanslarını karşılaştırabilmek için her iki model için de ilgili dağılım varsayımı tarafından üretilen aynı değerler kullanılmıștır. 
Bir diğer ifadeyle uzun dönemde Vasicek modeline göre $r_{\mathrm{T}}$ 'nin beklenen değeri, pozitif bir değer olan kendi uzun dönemli denge değerine $(\mu)$ eşit olacaktır. Uzun dönemli varyans da sınırlı $\left(\frac{\sigma^{2}}{2 \theta}\right)$ bir değer olacaktır. Bu nedenle de uzun dönemde denge değerinden sapmalar sınırlı kalacaktır (Sypkens, 2010: 49).

$\mathrm{Bu}$ açıklamalara rağmen Vasicek modelinin bazı dönemlerde ürettiği negatif faiz oranlarının yarattığı sorunlara bağlı olarak, CIR modeli geliștirilmiștir. Çünkü, CIR modelinde $2 \mu \theta>\sigma^{2}$ koşulunun sağlanması durumunda üretilen her bir nominal faiz oranının pozitif bir değere sahip olması da sağlanmış olmaktadır4.

$\mathrm{Bu}$ açıklamalar ışığında Vasicek modeline göre kuponsuz bonoların piyasa fiyatı Denklem (10)'da gösterildiği gibi hesaplanmaktadır5:

$P(t, T)=A(t, T) e^{-B(t-T) r_{0}}$

Burada,

$A(t, T)=\exp \left[(B(t, T)-T+t) \frac{\mu \theta^{2}-\frac{\sigma^{2}}{2}}{\theta^{2}}-\frac{\sigma^{2} B(t, T)^{2}}{4 \theta}\right]$ ve

$B(t, T)=\frac{1-e^{-\theta(T-t)}}{\theta}$ olmaktadır.

$\mathrm{Bu}$ bonolarının her vadeye tekabül eden spot faiz oranları ise Denklem (11)'de gösterildiği gibi hesaplanmaktadır:

$r(T)=\frac{\ln \left(\frac{1}{P(T)}\right)}{T}$

Burada $r(T)$, $T$ zamanında vadesi dolacak olan bonosunun spot faiz oranını ifade etmektedir.

$\mathrm{Bu}$ spot faiz oranlarına bağlı olarak da getiri eğrileri olușturulmaktadır. Bu getiri eğrileri cari dönemdeki faiz oranları $\left(r_{t}\right)$ ile başlamakta

4 Şu husus da belirtilmelidir ki özellikle 2007-2008 küresel finans krizi sonrasında gelişmiş ülke ekonomilerindeki kısa vadeli nominal faiz oranlarının negatif değerler aldıkları gözlemlenmiștir. Öyle ki İngiltere 2020 yılının Eylül ayında ilk defa negatif faizli bono ihraç etmiştir. Fakat, Türkiye gibi gelişen piyasa ekonomilerinde böyle bir durum gözlemlenmemiștir. $\mathrm{Bu}$ çalışmada da Türkiye ekonomisi üzerinde durulmaktadır. ve nihai olarak Denklem (12)'de gösterilen uzun dönemli faiz oranına (infinitely-long rate) $\left(r_{\infty}\right)$ yakınsamaktadır:

$r_{\infty}=\mu-\frac{\sigma^{2}}{2 \theta^{2}}$

$\mathrm{Bu}$ nedenle eğer $r_{t} \leq r_{\infty}-\frac{\sigma^{2}}{4 \theta^{2}}$ ise artan eğimli bir getiri eğrisi elde edilmektedir. Eğer $r_{\infty}+$ $\frac{\sigma^{2}}{2 \theta^{2}} \leq r_{t}$ ise azalan eğimli bir getiri eğrisi elde edilmektedir.

CIR modeline göre ise kuponsuz bonolarının piyasa fiyatı Denklem (13)'te gösterildiği gibi hesaplanmaktadır:

$P(t, T)=A(t, T) e^{-B(t-T) r_{0}}$

Burada,

$A(t, T)=\left[\frac{2 \gamma e^{(\theta+\gamma)(t-T) / 2}}{(\gamma+\theta)\left[e^{\gamma(t-T)}-1\right]+2 \gamma}\right]^{2 \theta \mu / \sigma^{2}}$

$B(t, T)=\left[\frac{2\left[\left(e^{(\gamma)(t-T)}\right)-1\right]}{(\gamma+\theta)\left[e^{\gamma(t-T)}-1\right]+2 \gamma}\right]$

ve $\gamma=\sqrt{\theta^{2}+\sigma^{2}}$ olmaktadır.

CIR modelinde uzun dönemli faiz oranı (infinitely-long rate) $\left(r_{\infty}\right)$ ise Denklem (14)'teki gibi hesaplanmaktadır:

$$
r_{\infty}=\frac{2 \theta \mu}{\gamma+\theta}
$$

\subsubsection{Vasicek ve CIR Modellerinin Performanslarının Analizi}

Vasicek ve CIR modellerinin parametreleri tahmin edildikten sonra hangi modelin Türk faiz oranı piyasası için daha uygun olduğunun belirlenebilmesi gerekmektedir. Bu amaçla bu

5 Getiri eğrileri spot faiz oranlarından oluşmaktadır. Bugünkü değer faktörleri ile forward verim eğrileri de spot faiz oranlarına dayanmaktadır.Bu nedenle Vasicek ve CIR modelleri spot faiz oranlarının tahminine odaklanmaktadır. Spot faiz oranları da özünde kuponsuz bonoların faiz oranlarına tekabül etmektedir. Bir diğer ifadeyle spot faiz oranları kuponsuz bonoların cari dönemdeki piyasa değerlerini bononun vade sonu değerine (nominal değerine) eşitleyen faiz oranlarıdır. 


\section{Ö. BÜBERKÖK̈̈}

çalışmada kayıp fonksiyonlarından (loss functions) yararlanılmıştır. Nitekim bu tür analizler literatürde yaygın bir şekilde kullanılmaktadır. Örneğin Byers ve Nowman (1998), Nowman (2001) ile Nowman ve Saltoğlu (2003) çalışmalarında bu amaçla ME (Mean Error, ME), MAE (Mean absolute error, MAE), MSE (Mean square error, MSE) ve RMSE (Root mean square error) kayıp fonksiyonları ile Theil's kriterlerinden yaralanmıștır.Ayrıca Ang ve Bekaert (2002) ile Bianchi (2020) de en uygun faiz oranı modelinin belirlenmesinde çalışmalarında benzer analizlere yer vermișlerdir. Cünkü bu tür kayıp fonksiyonları ile Vasicek ve CIR modelleri tarafından üretilen faiz oranlarının gösterge faiz oranlarına yakınsama dereceleri hesaplanabilmektedir. $\mathrm{Bu}$ nedenle bu çalışmada da ME, MAE, MSE, RMSE ve MAPE (Mean absolute percentage error, MAPE) kayıp fonksiyonları ile Theil's U kriterinden yararlanarak; modellerin gösterge faiz oranlarını öngörebilme (forecasting) performansları analiz edilmiștir. $\mathrm{Bu}$ tür analizlerde kayıp fonksiyonları ve Theil's U kriteri sıfıra ne kadar yakın değerler alırlarsa modelin performansının o kadar iyi olduğu sonucuna ulaşılmaktadır. Çünkü, bu durum ilgili modelin ürettiği faiz oranlarının gerçeğe o derece yakın olduğu anlamına gelmektedir. $\mathrm{Bu}$ yaklaşımların hesaplanma biçimleri sırasıyla Denklem (15), (16), (17), (18), (19) ve (20)'de gösterilmiştir:

$M E=1 /{ }_{T} \sum_{k=1}^{T}\left(r_{t, \text { tahmin edilen }}-r_{t, \text { gerçekleşen }}\right)$

$M A E=1 / \int_{T} \sum_{k=1}^{T}\left|r_{t, \text { tahmin edilen }}-r_{t, \text { gerçekleşen }}\right|$ (16)

$M S E=1 /{ }_{T} \sum_{k=1}^{T}\left(r_{t, \text { tahmin edilen }}-r_{t, \text { gerçekleșen }}\right)^{2}$

RMSE =

$\sqrt{1 / T \sum_{k=1}^{T}\left(r_{t, \text { tahmin edilen }}-r_{t, \text { gerçekleșen }}\right)^{2}}$

(18)
MAPE $=\frac{1}{T} \sum_{k=1}^{T} \frac{\left|r_{t, \text { tahmin edilen }}-r_{t, \text { gerçekleșen }}\right|}{\left|r_{t, \text { gerçekleșen }}\right|}$

Theil's $U=$

$\frac{\sqrt{1 / T \sum_{k=1}^{T}\left(r_{t, \text { tahmin edilen }}-r_{t, \text { gerçekleșen }}\right)^{2}}}{\sqrt{1 / T \sum_{k=1}^{T}\left(r_{\text {tahmin edilen }}\right)^{2}}+\sqrt{1 / T \sum_{k=1}^{T}\left(r_{t, \text { gerçekleșen }}\right)^{2}}}$

(20)

Burada $r_{t, \text { tahminedilen, }}$ CIR ve Vasicek modelleri tarafından üretilen faiz oranlarını; $r_{t, \text { gerçekleşen }}$, gerçek gösterge faiz oranlarını; $T$ ise toplam gözlem sayısını ifade etmektedir.

\subsubsection{Alternatif Volatilite Dönemlerinin Dikkate Alınması}

Çalışmada öncelikle yukarıda belirtilen analizler tüm dönem dikkate alınarak yapılmıştır. Ardından, gösterge faiz oranlarının volatilitesindeki farklı rejim dönemleri dikkate alınarak oluşturulan alt dönemler için Vasicek ve CIR modellerinin performansları ayrıca karşılaştırılmıştır.Burada gösterge faiz oranlarının volatilitesindeki farklı rejim dönemlerinin dikkate alınmasının temel nedeni volatilitenin finansal piyasalardaki en önemli risk göstergelerinden biri olmasıdır. Gösterge faiz oranının volatilitedeki farklı rejim dönemlerinin belirlenmesinde Inclan ve Tiao (1994) tarafından geliştirilen ve Sansó, Aragó ve Carrion-i Silvestre (2004) tarafindan modifiye edilen ICSS algoritmasindan yararlanılmıştır.

Inclan ve Tiao (1994) test istatistiği (IT) Denklem (21)'de gösterilmiştir:

$I T=\sup _{k}\left|\sqrt{T / 2} D_{k}\right|$

Fakat, IT test istatistiğinin sahip olduğu bazı dezavantajlara bağlı olarak Sansó vd. (2004) Kappa $1\left(\kappa_{1}\right)$ ve Kappa2 $\left(\kappa_{2}\right)$ test istatistiklerini geliştirmişlerdir. Bunu yanı sıra Sansó vd. (2004) finansal zaman serilerindeki yapısal kırılma sayılarının belirlenmesinde ilgili üç test istatistiği arasında bir tercih yapılması 
gerektiğinde, $\quad \kappa_{2}$ test istatistiğinden yararlanılmasını tavsiye etmişlerdir. $\mathrm{Bu}$ nedenle bu çalışmada IT ve $\kappa_{1}$ test istatistiklerine ait sonuçlara da yer verilmesine rağmen, nihai karar noktasında literatürle uyumlu bir şekilde $\kappa_{2}$ test istatistiğinden yararlanılmıştır. IT, $\kappa_{1} \quad$ ve $\quad \kappa_{2}$ test istatistiklerinin tamamının Ho hipotezleri "Volatilite serisinde yapısal kırılma yoktur" şeklindedir. $\kappa_{2}$ istatistiği Denklem (22)'de gösterilmiştir:

$\kappa_{2}=\sup _{k}\left|T^{1 / 2} G_{k}\right|$

\section{BULGULAR}

İncelenen dönem için gösterge faiz oranları Şekil 1'de, gösterge faiz oranlarında meydana gelen değişimler ise Şekil 2'de sunulmuştur6. Bilindiği gibi faiz oranları zaten yüzde olarak ifade edildiğinden diğerlerinin yanı sıra Bali ve Neftçi (2003:458) ile Neftçi'nin (2000:7) çalışmasında da olduğu gibi burada da faiz oranlarındaki değişimler hesaplanırken doğrudan faiz oranlarının bir önceki güne göre farkı alınmıştır. Şekil 1 incelendiğinde gösterge faiz oranlarının ana eğiliminin aşağı yönlü olduğu anlaşılmaktadır.

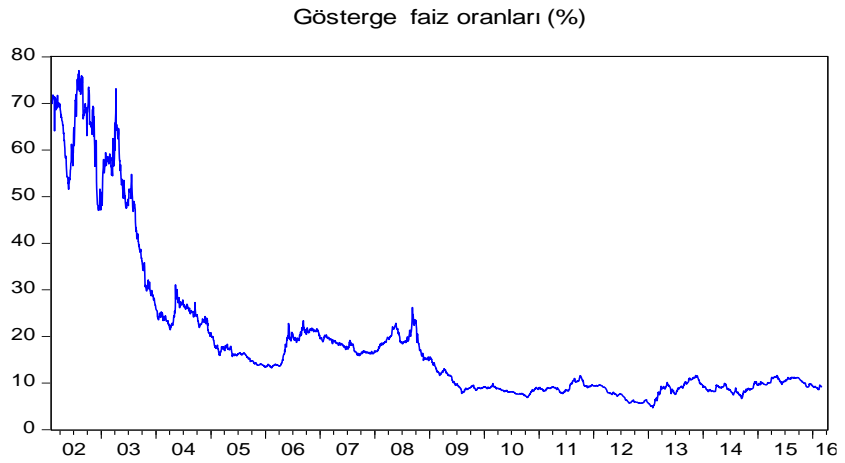

Şekil 1: Gösterge Faiz Oranları (Dikey eksen yüzde cinsinden faiz oranlarını, yatay eksen ise yılları göstermektedir)

\footnotetext{
6 Normalde ikinci bir yaklaşım olarak nominal faiz oranlarının logaritmik farkları alınarak da faiz oranlarındaki değișimler hesaplanabilmektedir. Fakat daha sonraki analizlerde görüleceği gibi Vasicek modeli negatif faiz oranları ürettiğinden bu değerlerin logaritması alınamamaktadır. Bu nedenle bu çalışmada daha sonraki aşamalar da dikkate alınarak birinci yaklaşım uygulanmıştır.
}

$\mathrm{Bu}$ durumun gerçekleșmesinde, 2001 yılının Şubat ayında yaşanan finansal kriz sonrasında Türkiye ekonomisinin daha liberal bir yapıya kavuşmasının ve merkez bankasının enflasyon hedeflemesine dayalı bir para politikası uygulamasına geçmesinin önemli etkilerinin olduğu düşünülmektedir. Şekil 2 incelendiğinde de gösterge faiz oranındaki değișkenliğin de azalan bir eğilim izlediği görülmektedir. $\mathrm{Bu}$ da geçmiş dönemlere nazaran faiz oranlarının öngörülebilirliğinin arttığı anlamına gelmektedir.

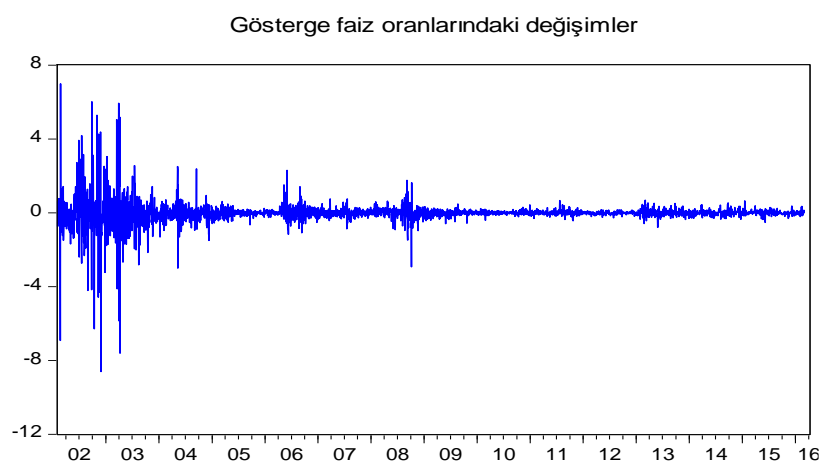

Şekil 2: Gösterge Faiz Oranındaki Günlük Değişimler (Dikey faiz oranlarındaki değişimleri, yatay eksen ise yılları göstermektedir)

Tüm dönem dikkate alınarak MLE yöntemi ile tahmin edilen CIR ve Vasicek modellerinin parametreleri Tablo 1'de sunulmuştur. Tablo 1 incelendiğinde model parametrelerinin beklenen kısıtları sağladığı görülmektedir. Çünkü, tüm model parametreleri pozitif değerler almaktadır. Ayrıca CIR modeli için $2 \theta \mu>\sigma^{2}$ koșulunun da sağlandığ anlașılmaktadır. Bu durum CIR modeline dayalı olarak yapılacak analizler sonucunda üretilecek tüm faiz oranlarının pozitif değerler alacağı anlamina gelmektedir. Son olarak da CIR modelinin parametrelerinin biraz daha yüksek çıktığı anlaşılmaktadır ${ }^{7}$.

7 Tablo 1'deki bulgular kullanılan paket program ve kodlar sonucunda elde edilen orijinal çıtılardır. Dikkat edilirse burada modellerin parametreleri yer almakla birlikte, bu parametrelerin istatistiki anlamlılığ konusundaki bilgiler yer almamaktadır. Bunun temel nedeni Vasicek ve CIR modellerinin stokastik faiz oranı modelleri olmalarına da bağlı olarak, literatürde bu modellerin kendi asli işlevleri olan spot faiz oranlarını 


\section{Ö. BÜBERKÖKÜ}

Tablo 1: CIR ve Vasicek Modellerinin Tahmini (MLE)

\begin{tabular}{|l|c|}
\hline Model & Model parametreleri \\
\hline CIR Modeli & 0.5335 \\
\hline$\theta$ (Ortalamaya dönme hızı) & 0.1111 \\
\hline $\begin{array}{l}\mu \text { (Faiz oranlarının uzun } \\
\text { dönemli ortalama değeri) }\end{array}$ & 0.1453 \\
\hline $\begin{array}{l}\sigma \text { (Nominal faiz oranlarının } \\
\text { standart sapması) }\end{array}$ & 0.4989 \\
\hline Vasicek Modeli & 0.1064 \\
\hline$\theta$ (Ortalamaya dönme hızı) & 0.0938 \\
\hline $\begin{array}{l}\mu \text { (Faiz oranlarının uzun } \\
\text { dönemli ortalama değeri) }\end{array}$ & \\
\hline $\begin{array}{l}\sigma \text { (Nominal faiz oranlarının } \\
\text { standart sapması) }\end{array}$ & \\
\hline $\begin{array}{l}\text { Not: Daha önce ifade edildiği gibi model parametreleri öncelikle } \\
\text { en küçük kareler yöntemi ile tahmin edilmiş ardından optimal } \\
\text { değerlerin bulunması için } \\
\text { yararlanılmıştır. }\end{array}$ \\
\hline
\end{tabular}

Model parametreleri tahmin edildikten sonra ilgili modellerden hangisinin gösterge faiz oranlarını daha iyi tahmin ettiklerinin belirlenmesine dönük analizlere geçilmiştir. $\mathrm{Bu}$ kapsamda 1 Ocak 2002 ile 4 Ağustos 2016 dönemi için CIR ve Vasicek modellerinin ürettiği faiz oranları ile gerçek faiz oranları Şekil 3'te birlikte sunulmuştur.

Şekil 3 incelendiğinde, beklenildiği gibi Vasicek modelinin ürettiği nominal faiz oranlarının bazı dönemlerde negatif değerlere sahip oldukları; CIR modelinin ürettiği faiz oranlarının ise sürekli bir şekilde pozitif değerler aldıkları gözlemlenmektedir. Ayrıca, görsel analize dayalı bulguların CIR modelinin performansının daha iyi olabileceğine işaret ettiği de ifade edilebilir. Çünkü, CIR modelinin ürettiği faiz oranlarının ana eğiliminin gösterge faiz oranları ile daha uyumlu olduğu görülmektedir.
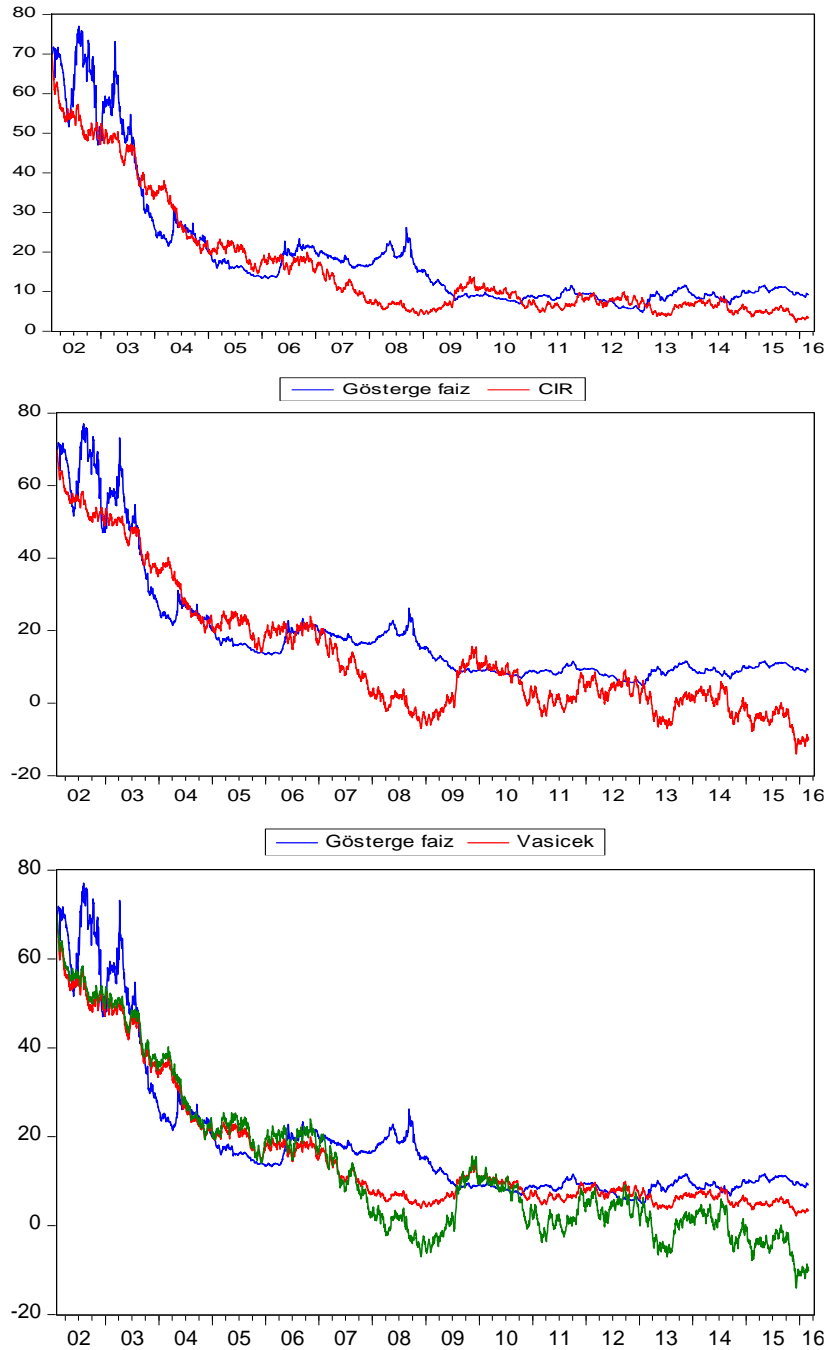

- Gösterge faiz — CIR - Vasicek

Şekil 3: CIR ve Vasicek Modellerinin Ürettiği Gösterge Faiz Oranları

(Dikey eksen yüzde cinsinden faiz oranlarını, yatay eksen ise yılları göstermektedir)

Tablo 2'de CIR ve Vasicek modellerinin ürettiği faiz oranlarına ilişkin betimleyici istatistikler sunulmuştur. $\mathrm{Bu}$ bulgulara bakıldığında da görsel analizi destekler ilave bulgulara ulaşılmaktadır. Çünkü, CIR modelinin ürettiği faiz oranlarının gerek aritmetik ortalamasının gerekse medyanının gösterge faiz oranlarına daha yakın olduğu görülmektedir. Ayrıca, CIR modelinin ürettiği faiz oranlarının standart sapmasının da Vasicek modelininkinden daha küçük olduğu görülmektedir. Bunun yanı sıra

tahmin edebildiği konusuna odaklanılmaktadır (Örneğin bakınız: Orlando vd., 2019; Herrala, 2009; Benninga ve Wiener, 1998). Nitekim ulusal yazındaki çalışmalarda da benzer bir durum söz konusudur (Örneğin bakınız: Önalan, 2009; Yolcu, 2005). 
incelenen dönem için gösterge faiz oranlarının sürekli pozitif değerler almalarına rağmen, Vasicek modelinin -\%14.06 seviyesine kadar ulaşabilen negatif faiz oranları ürettiği anlaşılmaktadır.

Tablo 2: CIR ve Vasicek modellerinin ürettiği gösterge faiz oranlarına ait betimleyici istatistikler (\%)

\begin{tabular}{|l|l|l|l|}
\hline & \multicolumn{1}{|c|}{ CIR } & \multicolumn{1}{|c|}{ Vasicek } & \multicolumn{1}{|c|}{$\begin{array}{c}\text { Gösterge } \\
\text { faiz }\end{array}$} \\
\hline $\begin{array}{l}\text { Aritmetik } \\
\text { ortalama }\end{array}$ & 16.05469 & 13.35378 & 18.92396 \\
\hline Medyan & 9.140146 & 7.119397 & 13.03000 \\
\hline Maksimum & 70.02000 & 70.0200 & 77.07999 \\
\hline Minimum & 2.158307 & -14.05637 & 4.670000 \\
\hline Std.sapma & 0.372407 & 0.599692 & 0.372407 \\
\hline $\begin{array}{l}\text { Gözlem } \\
\text { sayısı }\end{array}$ & 3674 & 3674 & 3674 \\
\hline
\end{tabular}

Not: Buradaki standart sapma değeri faiz oranlarında bir önceki güne göre meydana gelen değișimlerin standart sapmasidır.

Fakat, daha teknik ve net bulgulara ulaşılabilmesi için metodoloji bölümünde açıklanan kayıp fonksiyonları ile Theil's U kriterinin sonuçlarının analiz edilmesi gerekmektedir. $\mathrm{Bu}$ kapsamda elde edilen bulgular Tablo 3'te sunulmuştur. Bulgular incelendiğinde CIR modeli dikkate alınarak hesaplanan RMSE, MSE, MAE, MAPE ve ME kayıp fonksiyonları ile Theil's U kriterinin sıfıra daha yakın değerler aldıkları gözlemlenmektedir. Bu bulgular CIR modelinin performansının Vasicek modelinin performansından daha iyi olduğu anlamına gelmektedir. Bir diğer ifadeyle CIR modeli Vasicek modeline göre gösterge faiz oranlarını daha iyi öngörebilmektedir.

Tablo 3: Modellerin performanslarının karşılaştırılması

\begin{tabular}{|l|c|c|}
\hline & \multicolumn{1}{l|}{ CIR } & Vasicek \\
\hline RMSE & 0.0655 & 0.1003 \\
\hline MSE & 0.0043 & 0.0101 \\
\hline MAE & 0.0496 & 0.0798 \\
\hline Theil's U & 0.1404 & 0.2121 \\
\hline ME & -0.0287 & -0.0557 \\
\hline MAPE & 0.3062 & 0.6028 \\
\hline
\end{tabular}

Tüm dönem dikkate alınarak yapılan bu analizlere ilaveten, daha önce belirtilen gerekçelere bağlı olarak, gösterge faiz oranlarının volatilitesindeki farklı rejim dönemleri dikkate alınarak da ilgili tüm analizler yinelenmiștir. Nitekim incelenen dönem içerisinde gösterge faiz oranlarının volatilitesinde çeşitli yapısal değişimlerin yaşanmış olabileceği Şekil 2'den de gözlemlenebilmektedir. Dolayısıyla daha etkin analizlerin yapılabilmesi için bu değişimlerin dikkate alınmasının önemli olabileceği düşünülmektedir.

Tablo 4: $\kappa_{2}$ test istatistiğine göre belirlenen alternatif rejim dönemleri

\begin{tabular}{|l|l|}
\hline Rejim dönemleri & Tarihler \\
\hline Birinci rejim dönemi & 01.01 .2002 / 07.10.2003 \\
\hline İkinci rejim dönemi & 08.10 .2003 / 31.12.2009 \\
\hline Üçüncü rejim dönemi & 04.01 .2010 / 13.09.2011 \\
\hline $\begin{array}{l}\text { Dördüncü rejim } \\
\text { dönemi }\end{array}$ & 14.09 .2011 / 27.02.2012 \\
\hline Beşinci rejim dönemi & 28.02 .2012 / 16.05.2013 \\
\hline Altıncı rejim dönemi & 17.05 .2013 / 01.10.2013 \\
\hline Yedinci rejim dönemi & 02.10 .2013 / 08.06.2015 \\
\hline Sekizinci rejim dönemi & 09.06 .2015 / 04.08.2016 \\
\hline
\end{tabular}

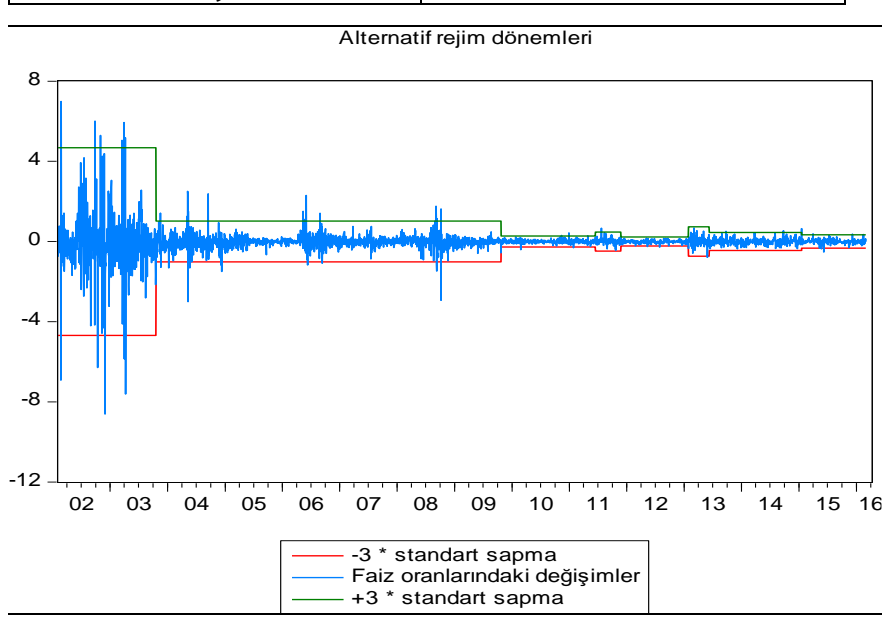

Şekil 4: $\kappa_{2}$ Test İstatistiğine Göre Belirlenen Alternatif Rejim Dönemleri (Dikey eksen faiz oranlarındaki değişimleri, yatay eksen ise yılları göstermektedir)

$\mathrm{Bu}$ doğrultuda ICSS algoritması uygulanarak, Şekil 2'de gösterilen ve gösterge faiz oranlarındaki günlük değişimi ifade eden serinin volatilitesinde çoklu yapısal kırılmaların gerçekleşip gerçekleşmediği incelenmiștir.Elde edilen bulgular kapsamında, gösterge faiz oranlarının volatilitesinde IT test istatistiğine göre $5, \kappa_{1}$ test istatistiğine göre 16 ve $\kappa_{2}$ test istatistiğine göre 7 adet yapısal 


\section{Ö. BÜBERKÖKÜ}

kırılma gerçekleşmiştir.Metodoloji bölümünde belirtilen gerekçelere bağlı olarak $\kappa_{2}$ test istatistiğinin sonuçları esas alındığında incelenen dönem için gösterge faiz oranının volatilitesinde 7 adet yapısal kırılmanın gerçekleştiği sonucuna ulaşılmaktadır. $\mathrm{Bu}$ nedenle ilgili dönemde gösterge faiz oranının volatilitesi için 8 ayrı rejim döneminin söz konusu olduğu ifade edilebilir. Bu dönemler rakamsal olarak Tablo 4'te, görsel olarak ise Şekil 4'te sunulmuştur. $\mathrm{Bu} 8$ ayrı rejim dönemine bakıldığında birinci rejim döneminde volatilitenin oldukça yüksek olduğu, ikinci rejim döneminde volatilitenin belli oranda gerilediği ardından gelen rejim dönemlerinde ise volatilitenin daha da azaldığı gözlemlenmektedir. Ayrıca, ikinci rejim döneminden sonraki yapısal kırılmaların belli dönemlerde etkin bir analize yer veremeyecek kadar az sayıda gözlem içeren aralıklarla gerçekleştiği de görülmektedir.

Bunun yanı sıra bu kırılmaların oluşturduğu rejim dönemleri arasında uzun süreli genel etkiye sahip büyük değişimlerin de yaşanmadığı anlaşılmaktadır. Bu nedenlerle CIR ve Vasicek modellerinin performanslarının etkin bir şekilde değerlendirilebilmesi amacıyla ve ikinci rejim dönemi sonrasında meydana gelen alternatif rejim dönemlerinin kendi içerisinde birinci ve ikinci rejim dönemine göre daha düşük bir volatilite düzeyine sahip tek bir rejim dönemi özelliği sergilemesi nedeniyle ikinci rejim döneminden sonraki tüm dönemler tek bir dönem olarak ele alınmıştır. Nitekim, volatilitenin bir ölçütü olarak ilgili dönemler için standart sapma değerleri hesaplandığında, birinci rejim dönemindeki standart sapma değerinin 1.56, ikinci rejim dönemindekinin 0.34 ve sonraki tüm dönemler tek bir rejim dönemi olarak değerlendirildiğinde ise standart sapma değerinin 0.13 olduğu belirlenmiştir. Bu nedenlerle 01.01.2002 ile 07.10.2003 dönemini kapsayan birinci rejim dönemi volatilitenin yüksek olduğu dönem, 08.10.2003 ile 31.12.2009 dönemini kapsayan ikinci rejim dönemi volatilitenin ortalama bir seyir izlediği dönem, 04.01.2010 ile 04.08.2016 dönemini kapsayan üçüncü rejim dönemi ise volatilitenin göreceli olarak düşük olduğu dönem olarak tanımlanıp; CIR ve Vasicek modellerinin performansları bu üç farklı dönem için ayrı ayrı incelenmiştir.

Öncelikle volatilite düzeyinin yüksek olduğu birinci rejim dönemi için CIR ve Vasicek modellerinin ürettikleri faiz oranları, gösterge faiz oranları ile birlikte Şekil 5 'te sunulmuştur. Şekil 5 incelendiğinde, Vasicek modelinin bu dönemde negatif değerler üretmediği anlaşılmaktadır. Ayrıca her iki modelin ürettiği faiz oranları arasında çok büyük farklar olmasa da Vasicek modelinin CIR modelinden biraz daha yüksek faiz oranları üreterek, gösterge faiz oranlarına daha yakın bir seyir izlediği gözlemlenmektedir.

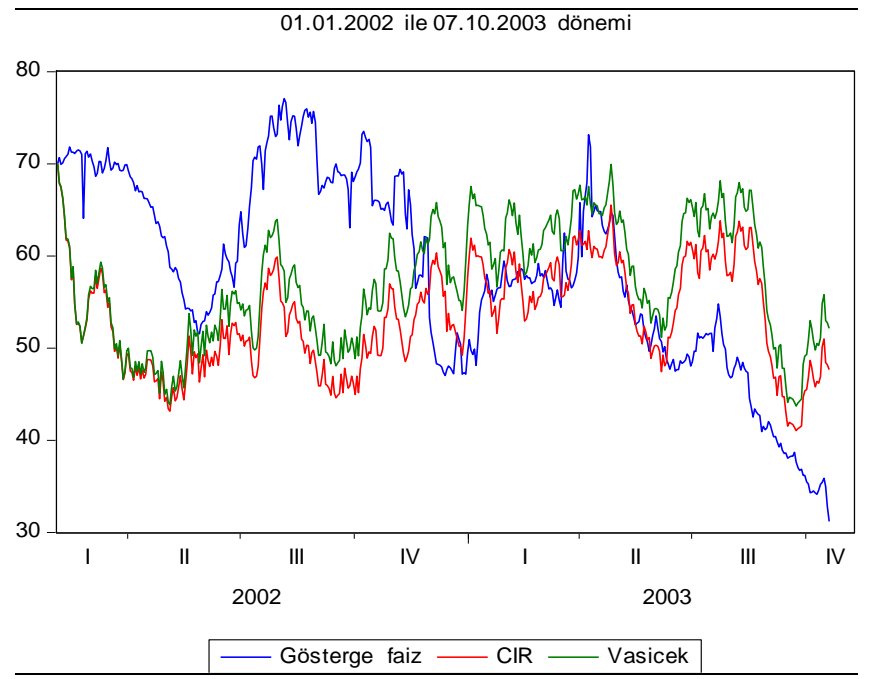

Şekil 5: CIR ve Vasicek Modellerinin Ürettiği Gösterge Faiz Oranları (Dikey eksen yüzde cinsinden faiz oranlarını, yatay eksen ise yılları göstermektedir)

Tablo 5'te sunulan betimleyici istatistiklere bakıldığında da Vasicek modelinin ürettiği faiz oranlarının hem aritmetik ortalamasının hem de medyanının gösterge faiz oranlarına daha yakın oldukları görülmektedir. Ayrıca, Vasicek modelinin ürettiği faiz oranlarının standart sapmasının da daha küçük olduğu anlaşılmaktadır. Daha teknik bulgulara ulaşılabilmesi için RMSE, MSE, MAE, MAPE ve ME kayıp fonksiyonları ile Theil's U kriterine ait sonuçlara bakıldığında (Tablo 6) da ilgili kayıp fonksiyonlarının ve Theil's U kriterinin Vasicek modeli için sıfıra daha yakın değerler aldıkları 
gözlemlenebilmektedir. Dolayısıyla birinci döneme ilişkin bulguların Vasicek modelinin daha iyi bir model olduğu sonucuna işaret ettiği anlaşılmaktadır.

Tablo 5: CIR ve Vasicek modellerinin ürettiği gösterge faiz oranlarına ait betimleyici istatistikler (\%)

\begin{tabular}{|l|l|l|l|}
\hline \multicolumn{2}{|c|}{ CIR } & Vasicek & Gösterge faiz \\
\hline $\begin{array}{l}\text { Aritmetik } \\
\text { ortalama }\end{array}$ & 50.14436 & 51.70697 & 58.42417 \\
\hline Medyan & 49.55007 & 51.19464 & 57.90000 \\
\hline Maksimum & 70.02000 & 70.02000 & 77.07999 \\
\hline Minimum & 36.44547 & 37.89708 & 32.82000 \\
\hline Std.sapma & 0.655092 & 0.594418 & 1.560568 \\
\hline Gözlem sayısı & 446 & 446 & 446 \\
\hline
\end{tabular}

Tablo 6: Modellerin performanslarının karșılaștırılması

\begin{tabular}{|l|c|c|}
\hline & \multicolumn{1}{l|}{ CIR } & \multicolumn{1}{l|}{ Vasicek } \\
\hline RMSE & 0.1104 & 0.0989 \\
\hline MSE & 0.0122 & 0.0098 \\
\hline MAE & 0.0892 & 0.0789 \\
\hline Theil's U & 0.1004 & 0.0089 \\
\hline ME & -0.0827 & -0.0671 \\
\hline MAPE & 0.1416 & 0.1258 \\
\hline
\end{tabular}

Volatilitenin ortalama bir seyir izlediği ikinci rejim dönemi ilişkin bulgulara gelince, CIR ve Vasicek modellerinin ürettikleri faiz oranları ile gösterge faiz oranları Şekil 6'da birlikte sunulmuştur. Şekil 6 incelendiğinde, Vasicek modelinin bu dönemde negatif değerler ürettiği görülmektedir. Ayrıca CIR modelinin Vasicek modelinden biraz daha yüksek faiz oranları üreterek, gösterge faiz oranlarına daha yakın bir seyir izlediği gözlemlenmektedir. Tablo 7'de sunulan betimleyici istatistiklere bakıldığında da CIR modeline ait faiz oranlarının hem aritmetik ortalamasının hem de medyanının gösterge faiz oranlarına daha yakın olduğu görülmektedir. Ayrıca, CIR modelinin ürettiği faiz oranlarının standart sapmasının da daha küçük çıktığı anlaşılmaktadır. RMSE, MSE, MAE, MAPE ve ME kayıp fonksiyonları ile Theil's U kriterine ait sonuçlara bakıldığında (Tablo 8) da ilgili yaklaşımların sunduğu değerlerin CIR modeli için sıfıra daha yakın oldukları gözlemlenebilmektedir. Dolayısıyla ikinci rejim döneme ilişsin bulguların CIR modelinin daha iyi bir model olduğu sonucuna işaret ettiği anlaşılmaktadır.

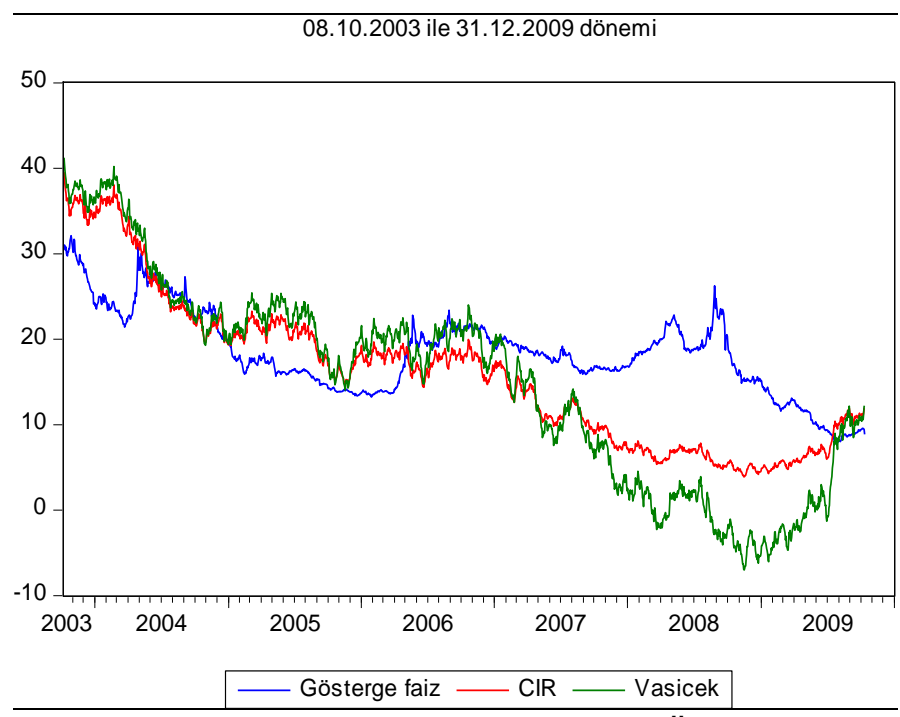

Şekil 6: CIR ve Vasicek Modellerinin Ürettikleri Gösterge Faiz Oranları (Dikey eksen yüzde cinsinden faiz oranlarını, yatay eksen ise yılları göstermektedir)

Tablo 7: CIR ve Vasicek modellerinin ürettiği gösterge faiz oranlarına ait betimleyici istatistikler (\%)

\begin{tabular}{|l|l|l|l|}
\hline & CIR & Vasicek & $\begin{array}{c}\text { Gösterge } \\
\text { faiz }\end{array}$ \\
\hline $\begin{array}{l}\text { Aritmetik } \\
\text { ortalama }\end{array}$ & 16.04226 & 14.97458 & 18.41024 \\
\hline Medyan & 16.24088 & 17.71271 & 18.29000 \\
\hline Maksimum & 39.55834 & 41.24915 & 32.12000 \\
\hline Minimum & 3.898187 & -7.004703 & 7.740000 \\
\hline Std.sapma & 0.370422 & 0.594670 & 0.338831 \\
\hline $\begin{array}{l}\text { Gözlem } \\
\text { sayısı }\end{array}$ & 1569 & 1569 & 1569 \\
\hline
\end{tabular}

Tablo 8: Modellerin performanslarının karșılaștırılması

\begin{tabular}{|l|l|l|}
\hline & \multicolumn{1}{|c|}{ CIR } & Vasicek \\
\hline RMSE & 0.0729 & 0.1062 \\
\hline MSE & 0.0053 & 0.0113 \\
\hline MAE & 0.0597 & 0.0817 \\
\hline Theil's U & 0.1954 & 0.2781 \\
\hline ME & -0.0237 & -0.0343 \\
\hline MAPE & 0.335 & 0.476 \\
\hline
\end{tabular}

Son olarak volatilitenin göreceli olarak düşük bir seyir izlediği üçüncü rejim döneminin sonuçlarına bakıldığında, Şekil 7'deki görsel bulguların Vasicek modelinin bu dönemde de negatif değerler ürettiği ve gösterge faiz oranlarından belirgin bir şekilde ayrıştı̆̆ 


\section{Ö. BÜBERKÖKÜ}

anlașılmaktadır.Tablo 9'da sunulan betimleyici istatistiklere bakıldığında da Vasicek modelinin negatif değerler ürettiği ve ikinci rejim dönemi ile birlikte ele alındığında Vasicek modelinin ürettiği toplam negatif değer sayısının 84 olduğu anlaşılmaktadır. $\mathrm{Bu}$ da toplam gözlem sayısının yaklaşı \% 23 'üne tekabül etmektedir. Ayrıca Tablo 9'daki betimleyici istatistikler Vasicek modelinin ürettiği değerlerin gösterge faiz oranlarından belirgin bir şekilde uzaklaştığı sonucuna işaret etmektedir. Çünkü, örneğin bu dönemde gösterge faiz oranlarının ortalaması \%9.791 iken Vasicek modelinin bu dönem için ürettiği faiz oranlarının ortalaması \%1.51 olmaktadir. Ayrica standart sapma değeri de oldukça yüksek çıkmaktadır. RMSE, MSE, MAE, MAPE ve ME kayıp fonksiyonları ile Theil's U kriterine ait sonuçlara bakıldığında da (Tablo 10) ilgili kayıp fonksiyonlarının ve Theil's U kriterinin belirgin bir şekilde CIR modelinin Vasicek modelinden daha iyi bir performans sergilediği sonucuna işaret ettikleri anlaşılmaktadır.

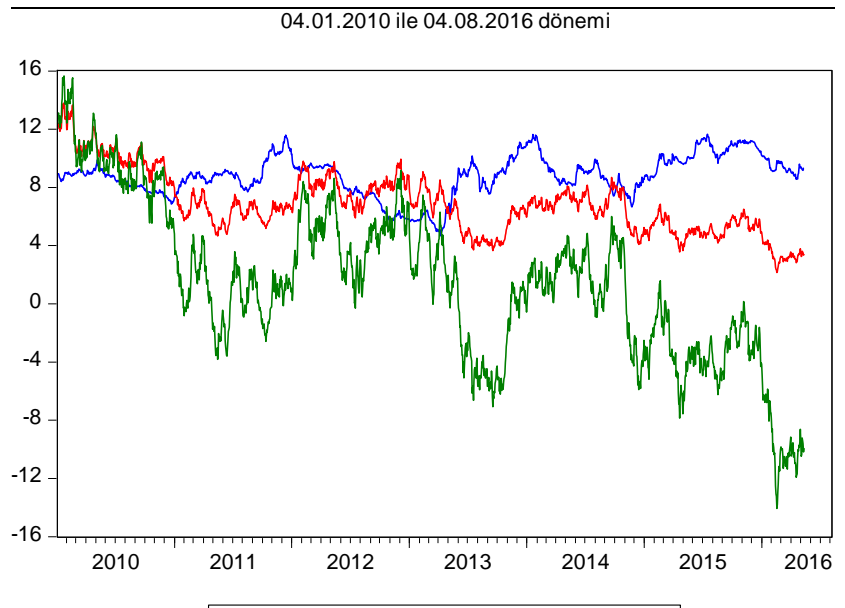

Şekil 7: CIR ve Vasicek Modellerinin Ürettiği Gösterge Faiz Oranları (Dikey eksen yüzde cinsinden faiz oranlarını, yatay eksen ise yılları göstermektedir)

$\mathrm{Bu}$ kapsamda üç ayrı döneme ilişkin tüm bulgular birlikte değerlendirildiğinde son iki rejim döneminde CIR modelinin, ilk rejim döneminde ise Vasicek modelinin daha iyi bir performans sergilediği anlaşılmaktadır. $\mathrm{Bu}$ bulgulara çalışmanın "ana eksenini" oluşturan tüm dönem sonuçları da eklendiğinde Türk faiz oranı piyasaları için CIR modelinin Vasicek modelinden daha iyi bir model olduğu ifade edilebilir.

Tablo 9: CIR ve Vasicek modellerinin ürettiği gösterge faiz oranlarına ait betimleyici istatistikler (\%)

\begin{tabular}{|l|l|l|l|}
\hline & CIR & Vasicek & $\begin{array}{c}\text { Gösterge } \\
\text { faiz }\end{array}$ \\
\hline $\begin{array}{l}\text { Aritmetik } \\
\text { ortalama }\end{array}$ & 6.901896 & 1.510160 & 8.790705 \\
\hline Medyan & 6.711819 & 1.566533 & 8.910000 \\
\hline Maksimum & 13.80317 & 15.66599 & 11.66000 \\
\hline Minimum & 2.158307 & -14.05637 & 4.670000 \\
\hline Std.sapma & 0.247674 & 0.605644 & 0.128136 \\
\hline $\begin{array}{l}\text { Toplam } \\
\text { gözlem sayısı }\end{array}$ & 1659 & 1659 & 1659 \\
\hline
\end{tabular}

Tablo 10: Modellerin performanslarının karșılaștırılması

\begin{tabular}{|l|l|l|}
\hline & \multicolumn{1}{|c|}{ CIR } & Vasicek \\
\hline RMSE & 0.0344 & 0.0947 \\
\hline MSE & 0.0012 & 0.0089 \\
\hline MAE & 0.0293 & 0.0782 \\
\hline Theil's U & 0.2131 & 0.6514 \\
\hline ME & -0.0188 & -0.0728 \\
\hline MAPE & 0.3233 & 0.851 \\
\hline
\end{tabular}

Çalışmanın giriș bölümünde bu stokastik faiz oranı modellerinin asli işlevlerinin spot faiz oranlarının hesaplanması, bugünkü değer faktörlerinin elde edilmesi, getiri eğrileri ile forward verim eğrilerinin oluşturulması olduğu ifade edilmişti. Çalışma bulgularının da CIR modelinin daha uygun bir model olduğu sonucuna işaret etmesi nedeniyle tüm dönem dikkat alınarak tahmin edilen CIR modeline ait spot faiz oranları, bugünkü değer faktörleri ve getiri eğrisi ile forward verim eğrisi için 6'şar aylık vadeler dikkate alınarak ileriye dönük 29 dönem için Şekil 8'de sunulmuştur.

Bulgular incelendiğinde CIR modelinin sunduğu getiri eğrisinin artan eğimli bir getiri eğrisi olduğu anlaşılmaktadır. Bu getiri eğrisi de piyasalarda en çok karşılaşılan getiri eğrisi türünü ifade etmektedir. Ayrıca bu getiri eğrisi iktisadi birimlerin ekonomik büyüme ve enflasyon oranlarına dönük ılımlı bir artış beklentisi içerisinde oldukları anlamına da gelmektedir. Bu noktanın önemi ise şu şekilde ifade edilebilir: 

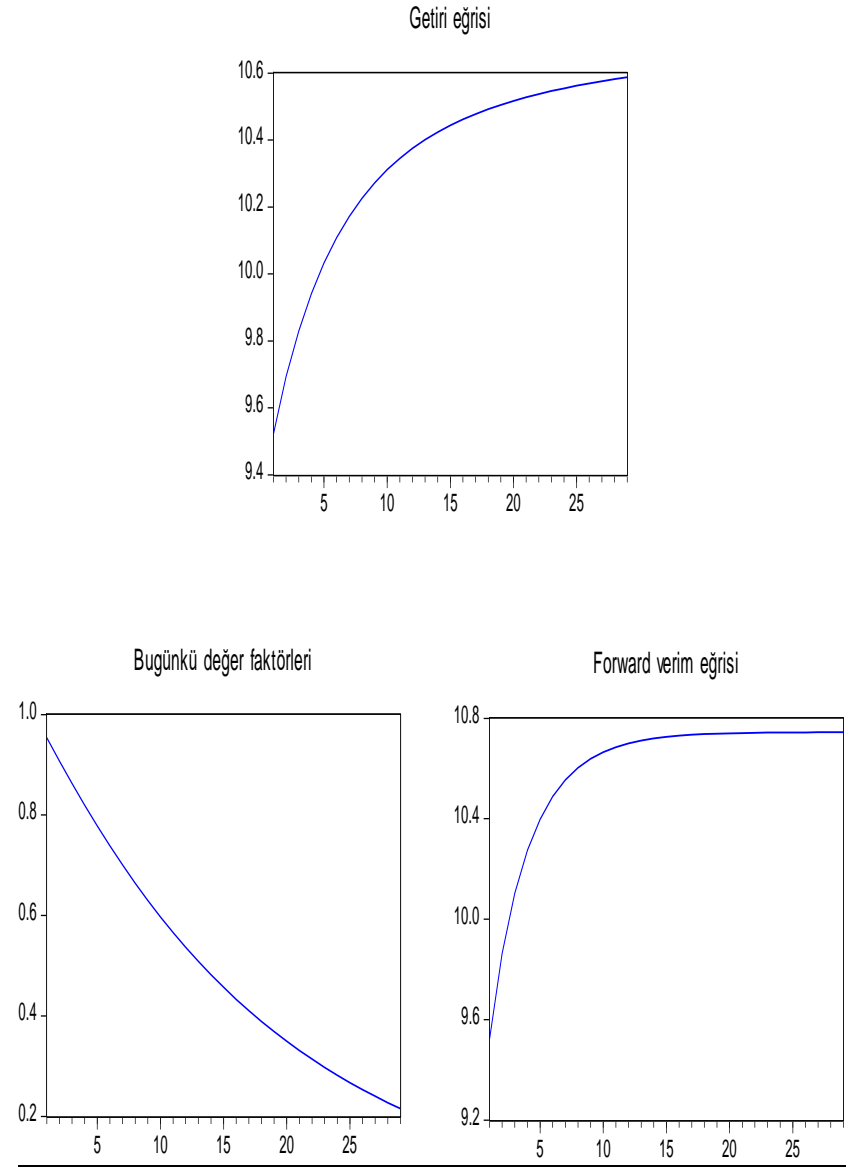

Not: İleriye dönük 29 dönem için 6'şar aylık vadeler dikkate alınarak çizilmiştir. Getiri eğrisi ilgili vadelere ait spot faiz oranlarının bir araya getirilmesi ile elde edilmektedir. Burada yatay eksen dönemleri, dikey eksen ise ilgili değerleri göstermektedir.

Şekil 8: CIR Modeline Ait Getiri Eğrisi, Bugünkü Değer Faktörleri ve Forward Verim Eğrisi

Tse (1995: 20) tarafından da ifade edildiği gibi bu tür tek faktörlü stokastik faiz oranı modellerinin temel dezavantajlarından biri bu modellerin getiri eğrisini oluşturan farklı vadelere sahip faiz oranları arasında bire bir oranında bir korelasyonun olduğunu, bir diğer ifadeyle bekleyişler hipotezinin en katı formunun (pure expectation hypothesis) geçerli olduğunu varsaymalarıdır. Çünkü bu tür modeller ancak bu varsayım altında tek bir faktörden (kısa vadeli faiz oranlarından) hareketle getiri eğrisini tahmin edebilmektedir. $\mathrm{Bu}$ varsayım da bu tür tek faktörlü modellerin üretebildiği getiri eğrisi formlarının uygulamada gözlemlen getiri eğrisi formlarına göre daha sinırlı / kisitlı olmasina yol açabilmektedir. Bu nedenle nihai aşamada bu tür modeller tarafından üretilen getiri eğrisi formlarının uygulamada gözlemlenen artan eğimli getiri eğrisi, azalan eğimli getiri eğrisi, düz getiri eğrisi ile tepeli (humped) getiri eğrisi şekillerinden hangilerini sunabildikleri de önemli bir tartışma konusudur. Bu nedenle bu çalışmada Benninga ve Wiener (1998), Anatolyev ve Korepanov (2003), Zhou ve Mamon (2012) ile Goard ve Hansen'in (2004) çalışmalarında da olduğu gibi çeşitli analizlere bağlı olarak en uygun model belirlendikten sonra (CIR modeli) bu model tarafindan sunulan getiri eğrisine ve bu getiri eğrisine bağlı olarak elde edilen diğer önemli değerlere de yer verilmiştir.

\section{DEĞERLENDIRME VE SONUÇ}

$\mathrm{Bu}$ çalışmada stokastik diferansiyel fark denklemlerine dayanan ve temel faiz oranı modelleri olan CIR ve Vasicek modelleri gösterge faiz oranlarına uygulanarak bu modellerden hangisinin Türk faiz oran piyasası için daha uygun olduğu belirlenmeye çalışılmıştır. CIR ve Vasicek modellerinin performansları analiz edilirken ME, MAE, MSE, MAPE ve RMSE kayıp fonksiyonları ile Theil's U kriterinden yararlanılmıștır. Tüm analizler hem tüm dönem hem de ICSS algoritmasına bağlı olarak belirlenen üç farklı volatilite dönemi için yapılmıştır.

Çalışma bulguları hem çalışmanın ana konusu oluşturan tüm dönem için hem de ICSS algoritmasına bağlı olarak belirlenen üç farklı volatilite döneminden iki tanesi için CIR modelinin daha iyi bir model olduğu sonucuna işaret etmektedir. Ayrıca, incelenen dönem içerisinde gösterge faizi oranlarının sürekli pozitif değerler almaların rağmen, Vasicek modelinin ürettiği faiz oranlarının yaklaşık \%23'ünün negatif değerlerden oluştuğu anlaşılmaktadır. Bunun yanı sıra çoğu durumda Vasicek modelinin ürettiği faiz oranlarının standart sapması da daha yüksek çıkmaktadır. $\mathrm{Bu}$ durum Vasicek modelinin ürettiği faiz oranlarındaki değişkenliğin daha yüksek olduğu anlamına gelmektedir.

Çalışma bulgularının uygulamaya dönük önemli bilgiler içerdiği düşünülmektedir. 


\section{Ö. BÜBERKÖK̈̈}

Öncelikle Türk faiz oranı piyasalarında çeşitli vadeler için ihtiyaç duyulan spot faiz oranlarının ve bugünkü değer faktörlerinin elde edilmesi, forward verim eğrilerinin tahmini ve getiri eğrilerinin olușturulmasında CIR modelinden yararlanılmasının daha doğru bir tercih olacağı anlaşılmaktadır. Bu nokta oldukça önemlidir. Çünkü getiri eğrileri iktisadi birimlerin ve piyasa katılımclarının ileriye dönük enflasyon ve ekonomik büyüme oranları konusundaki beklentilerini ifade etmektedir.Bu iki parametreye dönük beklentiler de özellikle enflasyon hedeflemesine dayalı bir para politikası uygulayan merkez bankları için politika kararlarını şekillendiren temel parametreler arasında yer almaktadır. Bu nedenle başta para politikaları olmak üzere daha etkin ekonomi politikalarının uygulanabilmesi için getiri eğrilerinin doğru bir şekilde modellenebilmesinin oldukça önemli işlevlerinin bulunduğu ifade edilebilir. Bunun yanı sıra, bilindiği gibi, yatırımcılar tahvil / bono piyasalarında çeşitli yatırım kararları verebilmekte ve bu piyasalarda arbitraj olanaklarının bulunup bulunmadığı konusunda bazı temel göstergelere ihtiyaç duyabilmektedirler. Forward verim eğrileri de yatırımclara vadeler arası yatırım stratejilerinin etkinliği ve olası arbitraj işlemleri konusunda önemli bilgiler sunmaktadır. Bu nedenle Vasicek modeli yerine CIR modeli tarafindan tahmini edilen forward verim eğrilerinden yararlanılmasının da daha doğru bir yaklaşım olabileceği anlaşılmaktadır.

$\mathrm{Bu}$ hususlara ilaveten CIR modelinin Türkiye'deki reel ve finansal sektör kuruluşlarının karşılaşabileceği faiz oranı riskinin etkin bir șekilde yönetilebilmesi açısından da önemli olduğu belirtilmelidir. Çünkü, Li vd. (2008: 31) tarafından da ifade edildiği gibi CIR modeli faiz oranlarına dayalı türev ürünlerin fiyatlanmasında kullanılan en önemli modellerden biridir. Türkiye gibi gelişen bir piyasa ekonomilerinde başta faiz oranları olmak üzere birçok finansal değişkenin volatilitesinin göreceli olarak yüksek olduğu bilinmektedir. Bunun yanı sıra 2007-2008 küresel finans krizi sonrasinda merkez bankalarının geleneksel olmayan para politikası uygulamalarına veya geleneksel para politikası uygulamalarına nazaran daha esnek bir para politikası karmasına yöneldikleri ifade edilebilir. Her ne kadar bu tür uygulamalar merkez bankasına önemli bir esneklik kazandırsa da bu tür uygulamalara giderek daha sık ve daha uzun süreli olarak başvurulması temel fonlama kanallarının kullanılması durumuna göre kısa vadeli faiz oranlarının volatilitesinin artmasına yol açabilmektedir. Tüm bu gelişmeler de faiz oranı riskinin yönetilmesini Türkiye ekonomisi için daha da önemli bir konu haline getirmektedir. $\mathrm{Bu}$ nedenle bu çalışma kapsamında CIR modelinin Türk faiz oranı piyasasına etkin bir şekilde uygulanabileceği sonucuna ulaşılmasının faiz oranı riskinin türev ürünlerle nasıl daha iyi bir şekilde hedge edilebileceğinin anlaşılabilmesi açısından da oldukça önemli olduğu düşünülmektedir.

Fakat, bu çalışmada kullanılan CIR ve Vasicek modelleri tek faktörlü stokastik faiz oranı modelleridir. Literatürde iki faktörlü modeller de bulunmaktadır. İki faktörlü modellerde ikinci stokastik faktör olarak uzun vadeli faiz oranları da dikkate alınmaktadır. Bu nedenle bu alanda daha sonra yapılacak çalışmalarda iki faktörlü CIR modelinden yararlanılabileceği düşünülmektedir.

Bunun yanı sıra Nelson-Siegel ile Svensson modellerinin özellikle merkez bankaları tarafından getiri eğrilerinin tahmininde yaygın bir șekilde kullanıldıkları bilinmektedir. Bu nedenle bu alanda daha sonra yapilacak çalışmalarda iki faktörlü CIR modelinin performansının Nelson-Siegel ile Svensson modellerinin performanslariyla karşılaştırllabileceği düşünülmektedir. 


\section{KAYNAKÇA}

Ahmed S.E., Nkurunziza S. ve Liu S. (2009). Improved estimation strategy in multi-factor Vasicek model. B. Schipp, W. Kräer W. (Ed.), Statistical Inference, Econometric Analysis and Matrix Algebra içinde (255-270. ss.), Physica:Verlag HD. https://link.Springer.com/chapter/10.1007 /978-3-7908-2121-5_17.

Albano, G., La Rocca, M. ve Perna, C. (2019). Small sample properties of $\mathrm{ml}$ estimator in Vasicek and CIR models: A simulation experiment. Decision in Economics and Finance, 42, 5-19.

Almeida, C. ve Vicente, J. (2008). The role of noarbitrage on forecasting: Lessons from a parametric term structure model. Journal of Banking \& Finance, 32, 2695-2705.

Anatolyev, S. ve Korepanov, S. (2003). The term structure of Russian interest rates. Applied Economics Letters,10,867-870.

Ang, A. ve Bekaert, G. (2002). Regime switches in interest rates. Journal of Business \& Economic Statistics, 20(2),162-182.

Babbs, S.H. ve Nowman, K.B. (1998). An application of generalized Vasicek term structure model to UK git-edged market: A Kalman filtering Analysis. Applied Financial Economics,8, 637-644.

Bakkaloglu, A., Aziz, T. ve Mahomed, F.M. (2004). Invariant criteria for the zero-coupon bond pricing Vasicek and Cox-Ingersoll-Ross Models. NTMSCI, 5(2), 29-46.

Bali, T.G. ve Neftci, S.N. (2003). Disturbing extremal behavior of spot rate dynamics. Journal of Emprical Finance, 10, 455-477.

Bao, J. ve Yuan, C. (2013).Long-term behavior of stochastic interest rate models with jumps and memory. Insurance: Mathematics and Economics, 53, 266-272.

Bayazit, D. (2004). Yield curve estimation and prediction with Vasicek model. (Yayımlanmamış Yüksek Lisans Tezi). Orta Doğu Teknik Üniversitesi Uygulamalı
Matematik Enstitüsü Finans Matematiği Bölümü, Ankara.

Benninga, S. ve Wiener, Z. (1998). Term structure of interest rates. Matematica in Education and Research, 7(2), 1-9.

Bianchi, M.L. (2020). Are multi-factor Gaussian term structure models still useful? An empirical analysis on Italian BTPs. Communication in Statistics-Simulation and Computation,12,1-29.

Bibbona,E., Panfilo, G. ve Tavella, P. (2008). The Ornstein-Uhlenbeck process as a model of a low pass filtered white noise. Metrologia, 45 (6): 117-126.

Brigo D. ve Mercurio F. (2001). Interest rate models theory and practice. Berlin: Springer, Heidelberg.

Byers, S.L. ve Nowman,K.B. (1998). Forecasting U.K. and U.S. interest rates using continuous time term structure models. International Review of Financial Analysis, 7(3), 191-206.

Chua, C.L., Suardi, S. ve Tsiaplias, S. (2013). Predicting short-term interest rates using Bayesian model averaging: Evidence from weekly and high frequency data. International Journal of Forecasting, 29, 442-455.

Cox, J., Ingersoll, J. ve Ross, S. (1985). A theory of the term structure of interest rates. Econometrica, 53, 385-407.

Csajkova, A. U. (2007). Calibration of term structure models. (Bitirme Tezi, Comenius University in Bratislava,Slovakya).Erişim adresi:

http://www.iam.fmph.uniba.sk/studium/efm /phd / ur ban ova / urbanova-thesis.pdf.

Çelik, İ. (2013). Markov zincirlerinin temel özellikleri ve çeşitli uygulamaları. (Yayımlanmamış yüksek lisans tezi). Ordu Üniversitesi Fen Bilimleri Enstitüsü Matematik Anabilim Dalı, Ordu.

Dağıstan, Ç. (2010). Quantifying the interest rate risk of bonds by simulation. 


\section{Ö. BÜBERKÖKÜ}

(Yayımlanmamış yüksek lisans tezi). Boğaziçi Üniversitesi Fen Bilimleri Enstitüsü Endüstri Mühendisliği Anabilim Dalı, İstanbul.

Doob, J.L. (1942). The Brownian movement and stochastic equations. Annals of Mathematics, 43(2), 351-369.

Georges, P. (2003). The Vasicek and CIR models and the expectation hypothesis of the interest rate term structure. Working PapersDepartment of Finance Canada 2003-17. Erişim adresi: http: //www.fin.gc.ca/scripts/Publication_Request $/$ request2e.asp?doc =wp2003-17e.pdf.

Goard, J. ve Hansen, N. (2004). Comparison of the performance of a time-depended shortinterest rate model with time-independent models. Applied Mathematical Finance, 11,147-164.

Herrala, N. (2009). Vasicek interest rate model: Parameter estimation evolution of the short term interest rate and term structure. (Lisans Bitirme Tezi, Lappeenranta University of Technology, Finlandiya). Erişim adresi: https://lutpub.lut.fi/bitstream/handle/10024 /43257/nbnfi-

fe200901141021.pdf?sequence $=3$.

Inclán, C. ve Tiao, G. C. (1994). Use of cumulative sums of squares for retrospective detection of changes of variance. Journal of The American Statistical Association, 89 (427) , 913-923.

Joshi, J.P. ve Swertloff, L. (1999). A users's guide to interest rate models: Application for structured finance. Journal of Risk Finance, 1(1),106-114.

Khalique, C. M. ve Motsepa, T. (2018). Lie symmetries, group-invariant solutions and conservation laws of the Vasicek pricing equation of mathematical finance. Physica A: Statistical Mechanics and its Applications, 505, 871-879.

Li, J., Clemons, C.B., Young, G.W. ve Zhu, J. (2008). Solutions of two-factor models with variable interest rates. Journal of
Computational and Applied Mathematics, 222 (1), 30-41.

Ma, C., Liu, J. ve Lan, Q. (2014). Studying term structure of SHIBOR with the two-factor Vasicek model. Abstract and Applied Analysis, 2014,1-7.

Mamon, R.S. (2004). Three ways to solve for bond prices in the Vasicek model. Journal of Applied Mathematics and Decision Sciences, 8(1), 1-14.

Moreno, M. ve Platania, F. (2015). A cyclical square-root model for the term structure of interest rates.European Journal of Operational Research, 241(1), 109-121.

Nath, P. ve Nowman, B. (2001). Estimates of the continuous time Cox-Ingersoll-Ross term structure model: Further results for the UK gilt-edged market. Applied Economics Lettres, 8, 85-88.

Neftcl, S.N.(2000). Value-at-risk calculations, extreme events, and tail estimation. The Journal of Derivatives, 7 (3) , 23-38.

Nowman, K.B. (2001). Gaussian estimation and forecasting of multi-factor term structure models with an application to Japan and the United Kingdom. Asia-Pacific Financial Markets, 8, 23-34.

Nowman, K.B. ve Saltoğlu, B. (2003). Continuous time and nonparametric modelling of U.S. interest rate models. International Review of Financial Analysis,12, 25-34.

Orlando, G., Mininni, R.M. ve Bufalo, M. (2019a). A new approach to forecast market interest rates through the CIR Model. Studies in Economics and Finance, 37 (2), 267-292.

Orlando, G., Mininni, R.M., Bufalo, M. (2019b). Interest rates calibration with a CIR model. The Journal of Risk Finance, 20 (4), 370-387.

Rogers, L.C.G. ve Stummer, W. (2000). Consistent fitting of one-factor models to interest rate data.Insurance: Mathematics and Economics,27, 45-63.

Önalan, Ö. (2009). Vasicek ve CIR modelleri kullanılarak oynaklık ve faiz oranlarının 
modellenmesi. Marmara Üniversitesi İ.İ.B.F. Dergisi, 27 (2), 329-344.

Sansó, A., Aragó, V. ve Carrion-I Silvestre, J. L. (2004). Testing for change in the unconditional variance of financial time series. Revista de Economía Financiera, 4, 32-53.

Schulmerich, M. (2005). Real options valuation. Berlin: Springer, Heidelberg.

Sinkala, W., Leach, P.G.L. ve O'hara, J.G.O. (2008). Zero-coupon bond prices in the Vasicek and CIR models: Their computations as group-invariant solutions. Mathematical Methods in the Applied Sciences,31,665-678.

Sypkens, R. (2010). Risk properties and parameter estimation on a mean reversion and GARCH models. (Yüksek Lisans Tezi, University of South Africa, Güney Afrika). Erişim adresi: http://uir.unisa.ac.za /bitst ream/handle/1 0500/4049/ disserta tion sypkens_r.pdf.

Şahin, H. ve Genç, İ.H. (2009).Kısa dönem faiz modellerinin Türkiye için ampirik analizi. BDDK Bankacılık ve Finansal Piyasalar, 3 (2), 107-119.

Tse, Y. K. (1995). Stochastic models of interest rates in economics, finance and actuarial science. Paper presented at the International Congress on Modelling and Simulation, Newcastle, New South Wales, Australia.https://ink.library.smu.edu.sg/soe_r esearch/714

van Elen, E. (2010). Term structure of forecasting. Does a good fit imply reasonable simulation results ?. (Lisans Bitirme Tezi,
Tilburg University, Hollanda). Erișim adresi: https://www.netspar.nl/assets/uploads/BA_ Emilevan_Elen_2010.pdf.

Vasicek, O. (1977). An equilibrium characterization of the term structure. Journal of Financial Economics, 5, 177-188.

Yolcu, Y. (2005). One-factor interest rate models: Analytic solutions and approximations. (Yayımlanmamış yüksek lisans tezi). Orta Doğu Teknik Üniversitesi Uygulamalı Matematik Enstitüsü, Finans Matematiği Bölümü, Ankara.

Zeytun, S. ve Gupta, A. (2007). A comparative study of the Vasicek and the CIR model of the short rate. Technical Report 124, Fraunhofer (ITWM),Nr. $124 . \quad$ Erişim adresi: https://kluedo.ub.uni-

kl.de/frontdoor/deliver/index/docld/1979/fi le/bericht124.pdf.

Zeytun, S. (2005). Stochastic volatility, a new approach for Vasicek model with stochastic volatility. (Yayımlanmamış Yüksek Lisans Tezi). Orta Doğu Teknik Üniversitesi Uygulamalı Matematik Enstitüsü Finans Matematiği Bölümü, Anakara.

Zhang, Y.G., Su, Y.P. ve Yang, B.C. (2009). An empirical analysis on term structure of SHIBOR using Vasicek and CIR models. Statistics \& Information Forum, 24 (6), 44-48.

Zhou,N. ve Mamon,R. (2012). An accessible implementation of interest rate models with markov-switching. Expert Systems with Applications,39,4679-4689. 